Article publié par le Laboratoire de Construction en Béton de l'EPFL

\begin{tabular}{|l|l|}
\hline Title: & $\begin{array}{l}\text { Influence of moment redistribution and compressive membrane action on } \\
\text { punching strength of flat slabs }\end{array}$ \\
\hline Authors: & Einpaul J., Fernández Ruiz M., Muttoni A. \\
\hline Published in: & Engineering structures \\
\hline DOI & $10.1016 /$ j.engstruct.2014.12.032 \\
\hline $\begin{array}{l}\text { Volume: } \\
\text { Pages: }\end{array}$ & $\begin{array}{l}\text { Vol. } 86 \\
\text { pp. 43-57 }\end{array}$ \\
\hline Country: & UK \\
\hline Year of publication: & 2015 \\
\hline Type of publication: & Peer reviewed journal article \\
\hline
\end{tabular}

Please quote as: Engineering structures, Vol. 86, UK, 2015, pp. 43-57. 


\title{
Influence of moment redistribution and compressive membrane action on punching strength of flat slabs
}

\author{
Jürgen Einpaul*, Miguel Fernández Ruiz, Aurelio Muttoni \\ Ecole Polytechnique Fédérale de Lausanne, ENAC, Lausanne, Switzerland
}

\section{A R T I C L E I N F O}

Article history:

Received 21 August 2014

Revised 6 November 2014

Accepted 16 December 2014

\section{Keywords:}

Punching

Continuous slabs

Critical Shear Crack Theory

Moment redistribution

Membrane effect

\begin{abstract}
A B S T R A C T
The punching shear strength of interior column connections of flat slabs has traditionally been investigated with isolated test specimens subjected exclusively to hogging bending moments. However, the behavior of such specimens is different from that of actual flat slabs, as the potentially beneficial phenomena of moment redistribution between hogging and sagging moments and compressive membrane action cannot take place in the conventional experiments. In the present paper, an axisymmetric numerical model is introduced that allows analyzing the role and significance of these effects on the flexural deformations of continuous flat slabs. Combined with the failure criterion of the Critical Shear Crack Theory, this model can be used to predict the punching capacities of such slabs. Comparisons are made to the results of some unconventional punching tests from the literature showing sound agreement between the modeling results and the experimental observations. The results suggest that the punching capacity of continuous slabs with low amounts of flexural reinforcement in the interior column regions may be underestimated in the current codes of practice.
\end{abstract}

(c) 2014 Elsevier Ltd. All rights reserved.

\section{Introduction}

The capacity of a reinforced concrete flat slab in the vicinity of columns is governed either by its flexural or shear strength. The flexural failure mechanism is well known and several analytical methods exist that allow determining the necessary reinforcement (from simple strip method to linear or non-linear finite element method or yield line theory). On the contrary, in many codes of practice $[1,2]$, the check of punching strength is performed with empirical formulas that have been established on the basis of fitting to available experimental results. It has been observed that the punching shear strength differs from one-way shear strength of beams. In order to model this difference but to avoid costly experiments on full continuous slabs, the tests of interior slab-column connections are normally performed on square, circular or octagonal isolated specimens with a concentrated load in the center. This test setup is aimed at reproducing the portion of the slab inside the line of moment contraflexure (assumed to be located at a radius of $r_{s}$ from the column center) of an actual continuous flat slab (Fig. 1(a)) and allows for the redistribution of hogging bending moment between radial and tangential directions after cracking of concrete and yielding of the reinforcement in the central portion of the element (Fig. 1(b)). This simplifies the testing procedure significantly, as only shear forces have to be applied at the edge of the

\footnotetext{
* Corresponding author.
}

element. However, conducting the tests on isolated elements might lead to inaccurate of even erroneous conclusions with respect to the behavior of an actual, continuous slab, as two aspects are neglected in that kind of experiments:

- In a continuous slab, some level of moment redistribution can occur between sagging moments in mid-span and hogging moments around the column (Fig. 1(c)). This phenomenon shifts the location of the line of contraflexure of the slab and influences its shear slenderness $r_{s} / d$.

- Isolated specimens expand laterally after flexural cracking on the support (Fig. 1(d)). This expansion (dilation) of an isolated specimen is constrained in a continuous slab. This phenomenon causes axial compression within the hogging moment area (Fig. 1(e)) that increases stiffness and strength of the slab in bending.

In this paper, the influence of these effects on flexural and punching strength will be analyzed using the approach of the Critical Shear Crack Theory [3] that constitutes the theoretical background of Model Code 2010 [4,5].

\subsection{Punching of flat slabs}

In 1960, Kinnunen and Nylander [6] proposed that the punching strength of a flat slab is related to the flexural deformations of the 
slab in the vicinity of a column. They suggested analyzing an axisymmetric isolated hogging moment area (Fig. 2(a)) that in an elastic slab with regular span lengths supported on small columns has a radius of approximately $0.22 \mathrm{~L}$ from the center of the column (Fig. 2(b)). As a parameter that describes the state of flexural deformations, the rotation of the slab at the line of moment contraflexure $\psi$ was proposed. The failure was assumed to occur due to crushing of a conical compression shell around the edge of the column when the tangential strain at the compressed face of the slab reaches a critical value. They proposed a simple law for determining the load-rotation relationship of an isolated hogging moment area and a method for designing the sagging reinforcement in order to ensure a similar behavior in continuous slabs.

Keeping the assumption that the punching capacity is related to flexural behavior, several researches have since improved the original model [7,8]. In the Critical Shear Crack Theory, Muttoni [3] proposed that the failure is governed by a parameter $\psi \cdot d$. This parameter is related to the opening width of flexural cracks due to flexural deformations in the shear-critical region (Fig. 2(c)), and thus considers both strain and size effects in a consistent manner [3]. The failure criterion proposed on the basis of a number of experiments on isolated specimens and theoretical considerations was given as [3]:

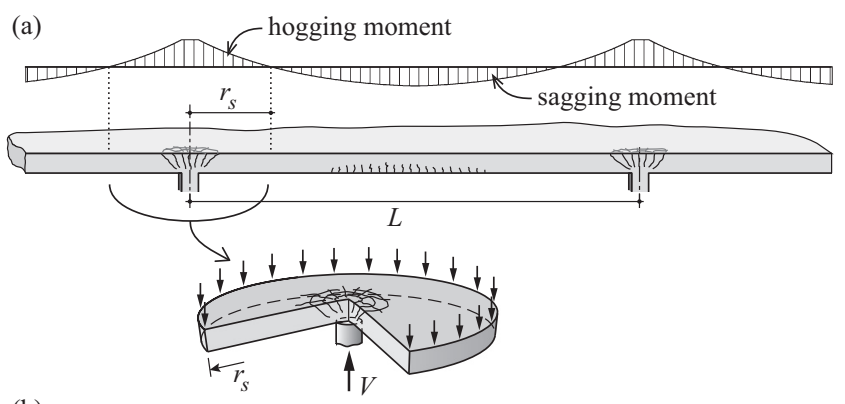

(b)

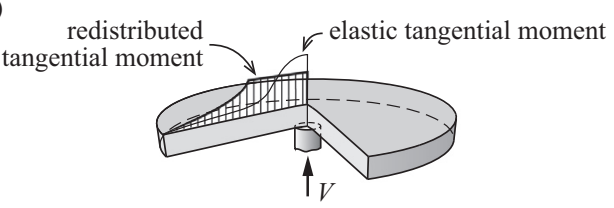

(c)

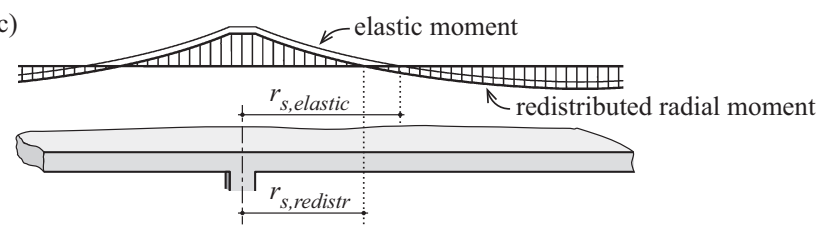

(d)

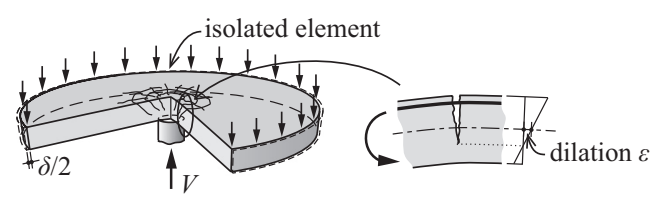

(e)

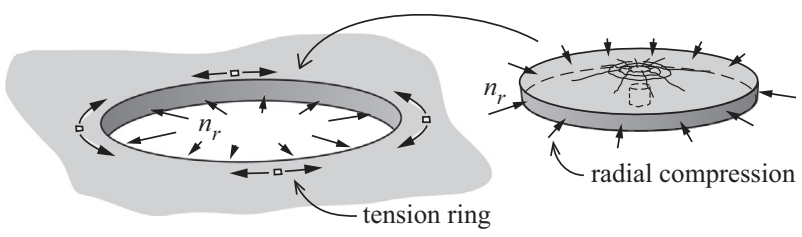

Fig. 1. (a) A continuous slab and a corresponding isolated test specimen; (b) redistribution of tangential moments in an isolated element after reinforcement yielding; (c) redistribution of radial moments in a continuous slab due to cracking and/or reinforcement yielding; (d) dilation of a reinforced concrete section in bending; (e) effect of the dilation of a hogging moment area on the rest of the slab. (a)

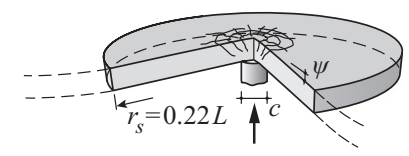

(b)

(c)
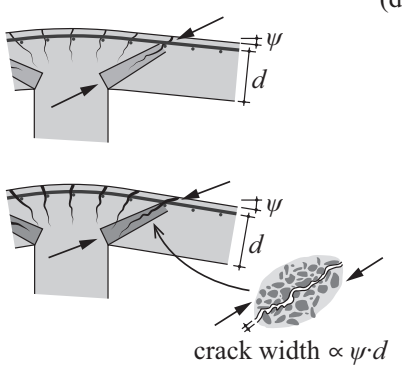

(d)
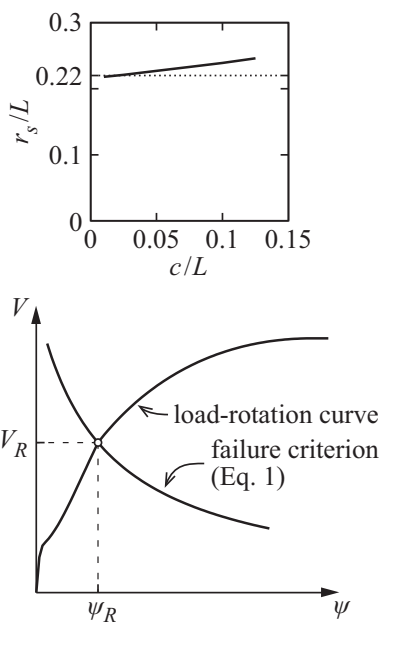

Fig. 2. (a) Isolated hogging moment area; (b) radius of the hogging moment area depending on the size of the column; (c) flexural deformations and cracking close to the column; (d) CSCT approach (according to [3]).

$V_{R}=\frac{0.75 \cdot b_{0} d \sqrt{f_{c}}}{1+15 \frac{\psi \cdot d}{d_{g 0}+d_{g}}}$

where $d$ is the effective depth of the slab, $b_{0}$ is the length of the control perimeter located at a distance $d / 2$ from the column face, $f_{c}$ is concrete cylinder compressive strength, $\psi$ is the rotation of the slab at the edge of an isolated specimen (or at the line of moment contraflexure in a general case) (Fig. 2(c)), $d_{g}$ is the maximum aggregate size and $d_{\mathrm{g} 0}=16 \mathrm{~mm}$ is a reference aggregate size. According to Muttoni [3], the punching strength can be calculated by using the failure criterion (Eq. (1)) in combination with a suitable load-rotation relationship (Fig. 2(d)). The failure criterion may be modified to incorporate in addition the contribution of shear reinforcement [9] or fibers [10]. In the case of large amounts of shear reinforcement, the punching capacity of a slab-column connection is limited by the crushing strength of the first strut between the column and the shear reinforcement. Failure in these cases is shown to be satisfactorily described with a failure criterion that refers to that of (Eq. (1)) but is multiplied with a factor $k_{\text {sys }}$ (depending on the type of shear reinforcement, for double-headed studs $k_{\text {sys }}=2.8$ is used) [9]. With reference to the influence of an axial compression $\sigma_{n}$ in the control perimeter, it can be taken into account by replacing the rotation $\psi$ with a modified rotation $\psi^{\prime}=\psi+45 \sigma_{n} / E_{c} \geqslant 0$ as shown in [11]. The load-rotation curve may be calculated with several levels of approximation [4] and it may also include the influence of slab continuity [12], normal forces and applied moments [11,13].

The general approach of the Critical Shear Crack Theory can also be used to treat slabs with irregular column layout and uneven loading [14] as well as punching of rectangular columns [15]. However, in the current paper, only cases that can be approximated by an axisymmetric model (interior column connections in regular span slabs under uniform loading) are considered.

\subsection{Behavior of confined slabs}

Stiffness of flexural response and punching capacity of actual flat slabs is known to exceed the values obtained by testing isolated specimens. Amongst others, in 1952, Ockleston [16] tested portions of an actual building in Johannesburg, South Africa and observed collapse loads sometimes several times higher than the predicted values. In 1972, Ladner et al. [17] performed punching tests on a reduced scale continuous flat slab and compared the 
values to the results obtained by testing round isolated slabs, noticing that the continuous slab showed both smaller deflections and higher punching loads than the isolated specimens. In 1992, Chana and Desai [18] reported tests made on a full scale shear reinforced slabs supported by a column in the center and linear supports at the edges, observing a significantly stiffer response than conventional specimens. In 2012, Choi and Kim [19] described tests on square slab elements with restrained rotation of the edges, reporting that the reinforcement ratio for sagging moment at the edges of the slab has as important influence on the punching strength as the amount of reinforcement for hogging moment above the support. However, compared to the vast amount of conventional punching tests, reports of tests on large scale continuous or restrained slabs remain scarce.

Significant effort has been made by researchers to evaluate the influence of membrane action on the flexural deformations and strength of slabs. Traditional yield line analysis (that neglects the influence of in-plane forces) results in plastic flexural strength $V_{\text {flex,yl }}$ that is normally independent on the deflection of the center point of the slab (Fig. 3(a)). Methods based on rigid-plastic analysis [20-22] allow modeling the dome effect of the forces arising from the changes of geometry. Assuming infinite in-plane stiffness, these methods lead to a maximum flexural strength value at zero deflection and subsequent decrease of flexural strength with increasing deflection due the reduction of the height of the compression arch (Fig. 3(b)). When the magnitude of the deflection is close to the thickness of the slab, the flexural strength approaches the unconfined yield line strength as the height of the compression arch reduces to zero. If the slab is equipped with sufficient amount of longitudinal reinforcement that is properly anchored at the

(a)

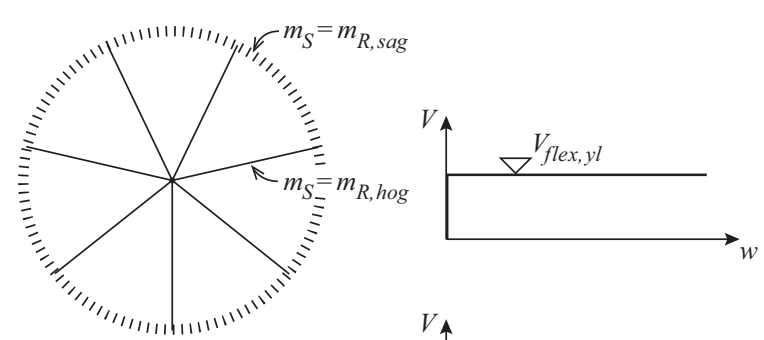

(b)
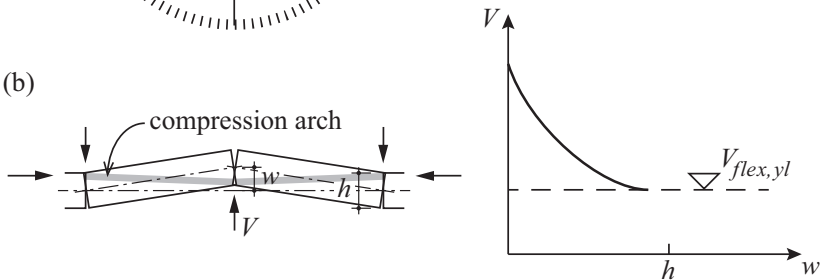

(c)
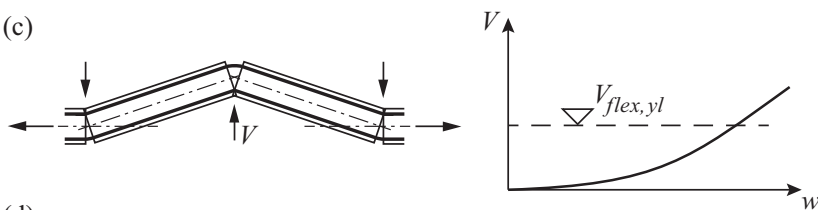

(d)

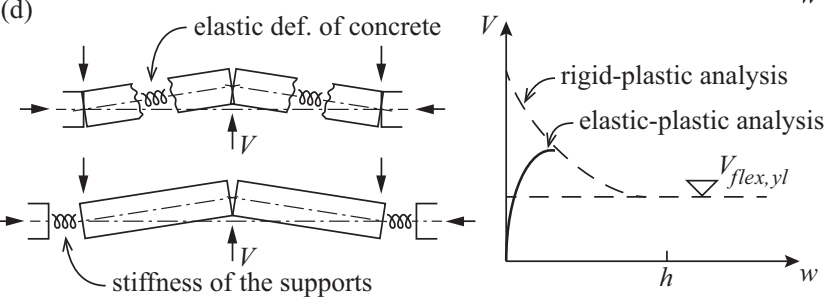

Fig. 3. (a) Flexural strength of a slab in the vicinity of the support according to yield line analysis; (b) influence of compressive membrane action, rigid-plastic analysis; (c) tensile membrane action; (d) compressive membrane action, elastic-plastic analysis. supports, tensile membrane action may arise (Fig. 3(c)). However, this resisting mechanism can only be activated in the presence of very large deformations and can be used in the engineering practice only for extreme cases as post-failure behavior $[23,24]$. This kind of membrane action is not described in the present paper.

The rigid-plastic analysis (Fig. 3(b)) assumes that the influence of the in-plane deformations of the slab and the lateral displacement of the supports are negligible compared to the influence of the changes of geometry. Therefore, in the case of small deflections (which is the most relevant regime for engineering applications and the main interest of this paper), an elastic-plastic analysis [25] has to be performed. If the surrounding structural elements are significantly stiffer than the slab, an assumption can be made that the stiffness of the lateral supports is infinite. Therefore, only the elastic deformations of concrete have to be taken into account in order to determine the ascending branch of the load-deflection curve [26] (Fig. 3(d)). This approach has been accepted by some codes of practice [27] as a basis of a design formula for designing bridge deck slabs between laterally stiff beams. However, these assumptions are not valid in the cases where the surrounding elements are not significantly stiffer than the slab. In these occasions, the stiffness of the supports has to be taken into account. In a simplified manner, this can be done by attributing the lateral supports a stiffness value that describes both the rigidities of the slab and of the restraining elements (Fig. 3(d)). In that case, the horizontal support reaction necessary to create the compression arch only will be generated at non-zero deflections. However, determining a suitable stiffness is still performed empirically in most cases [28-30].

Another possible approach for predicting the flexural behavior is using non-linear finite element analysis [31]. However, this requires a certain level of experience and may not be always advisable for design purposes.

\section{Numerical model for determining the flexural deformations of an axisymmetric slab}

\subsection{Axisymmetric numerical model}

In this section, a numerical approach is presented to obtain, in a general manner, a suitable load-rotation relationship to characterize continuous flat slabs around inner columns. The model in developed for axisymmetric cases. Extension to non-axisymmetric geometries is discussed in Appendix A of this paper. A region of the slab around an interior column is divided into axisymmetric elements (Fig. 4(a)) [12,32]. For each element, equations for the equilibrium of moments (2) and forces (3) as well as for the geometrical compatibility of deformations due to bending (4) and normal force (5) are written (notation in Fig. 4(b) and (c)):

$$
\begin{aligned}
& m_{r, i+1} \cdot r_{i+1}-m_{r, i} \cdot r_{i}-m_{t, i} \cdot \Delta r_{i}+v_{i+1} \cdot \Delta r_{i} \cdot r_{i+1}+q_{i} A_{i}\left(r_{q, i}-r_{i}\right)=0 \\
& n_{r, i+1} \cdot r_{i+1}-n_{r, i} \cdot r_{i}-n_{t, i} \cdot \Delta r_{i}=0 \\
& \chi_{t, i}=\frac{-\psi_{i}+\chi_{r, i} \cdot \Delta r_{i} / 2}{r_{i}+\Delta r_{i} / 2} \\
& \varepsilon_{t, i}=\frac{u_{i}+\varepsilon_{r, i} \cdot \Delta r_{i} / 2}{r_{i}+\Delta r_{i} / 2}
\end{aligned}
$$

Eqs. (2)-(5) can be used in combination with suitable momentcurvature and moment-dilation relationships for the considered level of axial load. This can be generally modeled with a layered non-linear sectional analysis. To facilitate the calculation procedure, a simpler multi-linear law is used in the current paper 
(a)

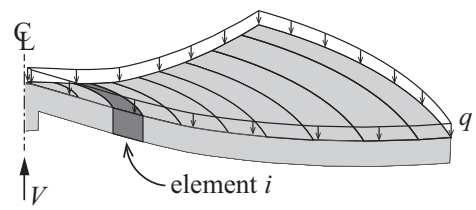

(b)

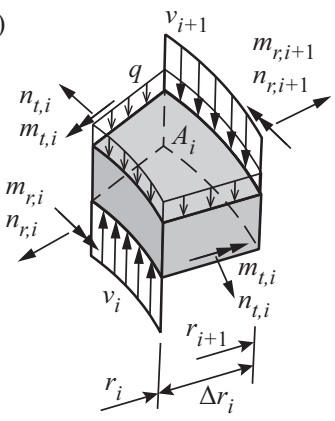

(c)

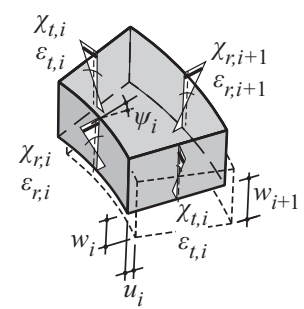

(d)

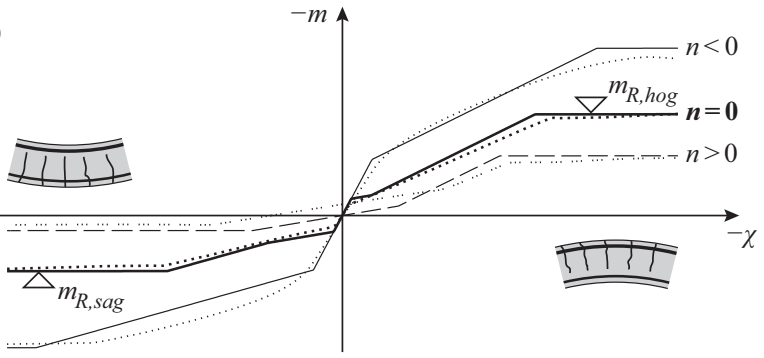

(e)

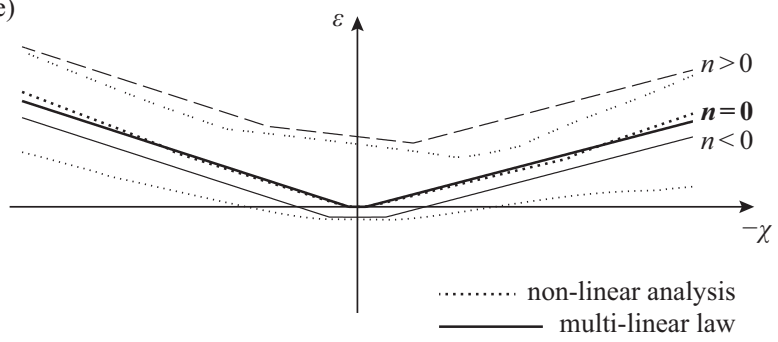

Fig. 4. (a) Axisymmetric element; (b) internal forces acting on the element; (c) deformations and displacements of the element; ( $\mathrm{d}$ and e) moment-curvature ( $m-$ $\chi)$ and dilation-curvature $(\varepsilon-\chi)$ relationships for different levels of axial force $(n)$ : results of a non-linear sectional analysis and the simplified multi-linear law (refer to Appendix B).

(Fig. 4(d) and (e)), where different branches of the multi-linear law are related to uncracked, cracked and reinforcement yielding regimes:

$(m, n)=f(\chi, \varepsilon)$

For the details about the derivation of the multi-linear law, refer to Appendix B. The sectional response is calculated independently in tangential and radial directions (a value equal to 0 is set for the Poisson's coefficient).

Eqs. (2)-(5) can be used to find the internal forces and deformations at the outer edge of an element if the internal forces at the inner edge of the element are known. The increase of rotation and vertical as well as horizontal displacements within an element can also be obtained. Therefore, by assuming a state of deformations $(\chi, \varepsilon)$ at the inner edge of the centermost element and repeating the calculation for each subsequent element, taking into account the external loads $q$ applied on the slab, two boundary conditions (static or kinematic) have to be fulfilled at the edge of the slab. The response of the slab can thus be determined by finding for each loading case the state of deformations in the center (a)

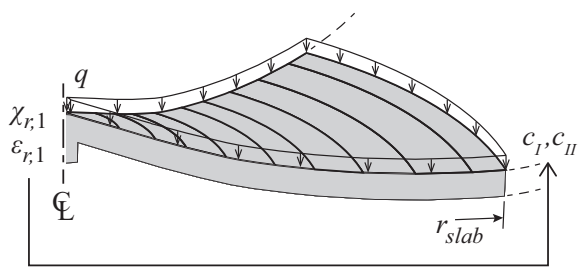

(b) isolated slab

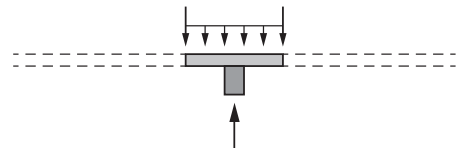

(c) self-confined slab

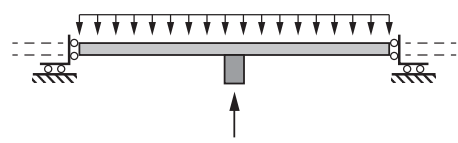

(d) fully confined slab

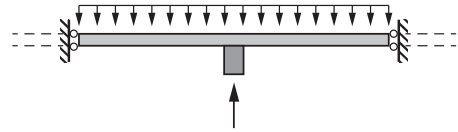

Fig. 5. (a) Axisymmetric calculation model; (b) edge conditions for an isolated slab; (c) edge conditions for a slab without external confining elements (self-confined); (d) edge conditions for a slab with perfectly rigid external confining elements.

that leads to the appropriate boundary conditions. This is done by means of an iterative calculation procedure.

\subsection{Boundary conditions}

The boundary conditions in at the edge of the slab are:

- for an isolated specimen, the radius of the axisymmetric calculation model corresponds to the radius of the specimen. Radial moment at specimen's edge has to be zero $\left(m_{r, \text { edge }}=0\right)$ and if the loading system is designed as to avoid in-plane forces and no prestressing is applied, the radial normal force at the edge of the slab has to be zero as well $\left(n_{r, \text { edge }}=0\right)$;

- for a continuous slab, the radius of the model $r_{\text {slab }}$ corresponds to the distance between the column and the symmetry line in mid-span. The first boundary condition is therefore zero rotation at the edge of the model $\left(\psi_{\text {edge }}=0\right)$. The radius of the slab $r_{\text {slab }}$ is selected so that in the elastic uncracked phase, the axisymmetric model has to yield the same radius of moment contraflexure $r_{s}$ of $0.22 \mathrm{~L}$ as it is in a regular continuous slab. This leads to the choice of $r_{\text {slab }} \cong 0.7 L$ (refer to Appendix A for discussion). The second boundary condition may be:

- for a flat slab on supports that carry only vertical reactions (a self-confined slab), the second boundary condition is $n_{r, e d g e}=0$ (Fig. 5(c));

- for a flat slab that is perfectly confined between external elements (like, for example, very stiff shear walls), the second boundary condition is $u_{\text {edge }}=0$ (Fig. $5(\mathrm{~d})$ ).

Other cases can also be easily modeled, including tests on additionally confined isolated slabs, slabs with partially rotationrestrained edges, or slabs with bending moments applied at some distance from the center.

\section{Modeling results}

\subsection{Influence of slenderness}

As provided by Eq. (1) (see also Fig. 2(d)), punching capacity decreases for increasing rotations of the slab as wider cracks open 
(a)

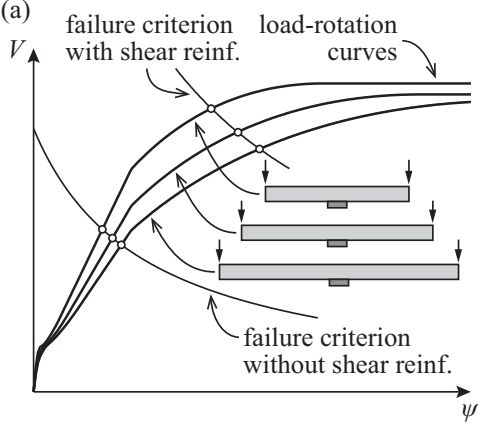

(b)

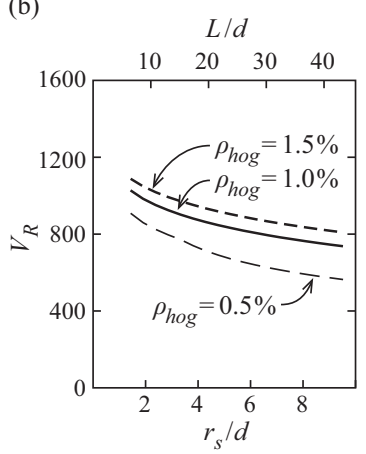

Fig. 6. Influence of the slenderness of a specimen on its punching capacity according to the CSCT [3]: (a) Intersections of load-rotation curves for specimens ( $\rho=1.0 \%$ ) with different slenderness ratios and the failure criterion; (b) influence of the slenderness ratio of a slab $\left(r_{s}=0.22 L\right)$ on the punching strength for different reinforcement ratios (parameters: $h=250 \mathrm{~mm}, d=210 \mathrm{~mm}, c=260 \mathrm{~mm}, f_{c}=35$ $\mathrm{MPa}, f_{y}=550 \mathrm{MPa}, c=260 \mathrm{~mm} ; d_{g}=16 \mathrm{~mm}$ ).

in the vicinity of the column. As a consequence, the load-rotation response of an isolated specimen depends significantly not only on the reinforcement ratio for the hogging moment but also on the shear slenderness $\left(r_{s} / d\right)$ of the specimen (Fig. 6(a)). Therefore, a decreasing slenderness increases the punching strength of a specimen (Fig. 6(b)). This effect is well known and even considered in some empirical formulas [33] but is not taken into account in most codes of practice $[1,2]$.

It follows that the correct choice of test specimen slenderness is important in order to model suitably the behavior of an actual slab. A common approach for selecting a representative specimen size is to determine the location of the line of moment contraflexure by assuming a linear-elastic material response and an uncracked behavior. In this manner, for a continuous slab supported on regularly spaced small supports and assuming an elastic uncracked behavior, the line of moment contraflexure is located approximately at a radius of $0.22 \mathrm{~L}$ from the column axis [6] (Fig. 2(b)). However, as the actual response of reinforced concrete is non-linear and redistribution of bending moments may develop, this assumption might not be correct for all potential load levels.

In Fig. 7(a), the distance $r_{s}$ between the column axis and the line of moment contraflexure is presented depending on the value of the support reaction, calculated using the axisymmetric numerical model with distributed load. In-plane forces are neglected in this analysis in order to investigate only on the influence of moment redistribution. It can be seen that after an initial elastic uncracked phase, the line of moment contraflexure shifts closer to the column (the shear slenderness decreases) due to the loss of stiffness in the hogging moment area near the column. After cracking of concrete due to sagging moment in mid-span, the shear slenderness starts to increase again. At the load levels where the radial reinforcement in the hogging moment area has started to yield, the line of moment contraflexure approaches again the elastic estimate. This occurs because in this range, the stiffnesses of the hogging and sagging moment areas (at column and mid-span, respectively) are similar. The shear slenderness starts to decrease again once that all the hogging reinforcement is yielding (which would correspond to the flexural failure of an isolated specimen). Similar results regarding the changes of shear slenderness due to the non-linear behavior of reinforced concrete were obtained using a non-linear finite difference analysis of continuous flat slabs [34].

\subsection{Influence of moment redistribution}

Flexural reinforcement of flat slabs is nowadays conventionally designed using linear-elastic finite element programs (with or without a redistribution of hogging moments) or simplified analytical methods, as the "direct design method" [2]. Both approaches normally result in placing relatively large amounts of flexural reinforcement in the support regions. However, many existing flat slabs have also been designed using the theory of plasticity (yield line method or strip method), which allows the designer freely choose the amount of moment redistribution. This leads to potentially large variation in the ratios between the amount of reinforcement at the support and in mid-span. The method described in the present paper allows taking into account the influence of the actual reinforcement distribution and is thus a very useful tool to investigate existing flat slabs with unusual hogging-to-sagging reinforcement distributions.

As already shown in Fig. 7(a), moment redistribution also takes place in elastically designed slabs due to non-linear behavior. Fig. 7(b) presents a load-rotation curve that is calculated using the axisymmetric model representing a continuous slab with twice the amount of hogging reinforcement compared to the sagging reinforcement. As a comparison, the load-rotation curve of a corresponding isolated specimen with $r_{s}=0.22 \mathrm{~L}$ is also shown. The continuous slab is loaded with distributed load, whereas the isolated specimen is loaded with an identical distributed load and a linear load at the edge of the specimen that corresponds to the shear force of the distributed load on the rest of the slab. It can be seen that the rotation of the continuous slab for a given level of load (compared to the one of an isolated specimen) depends on its (a)

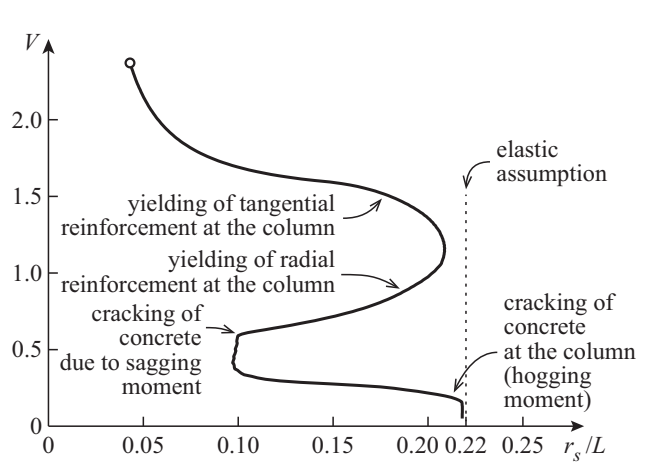

(b)

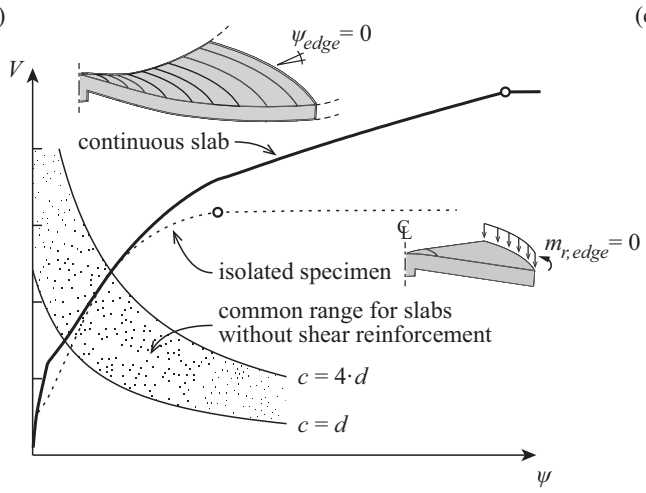

(c)

yield line pattern at flexural failure

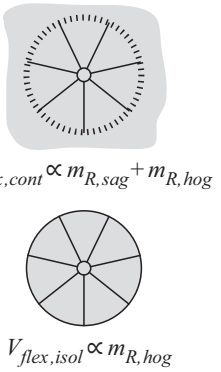

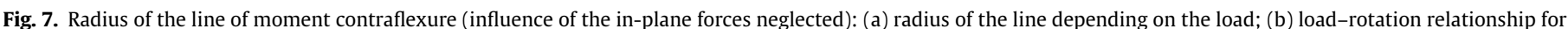

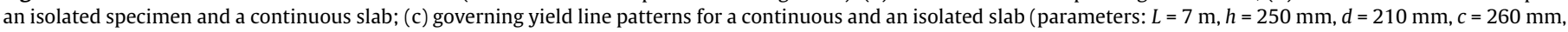
$f_{c}=35 \mathrm{MPa}, f_{y}=550 \mathrm{MPa}, c=260 \mathrm{~mm} ; d_{g}=16 \mathrm{~mm} ; \rho_{\text {hog }}=1.0 \% ; \rho_{\text {sag }}=0.5 \%$ ). 


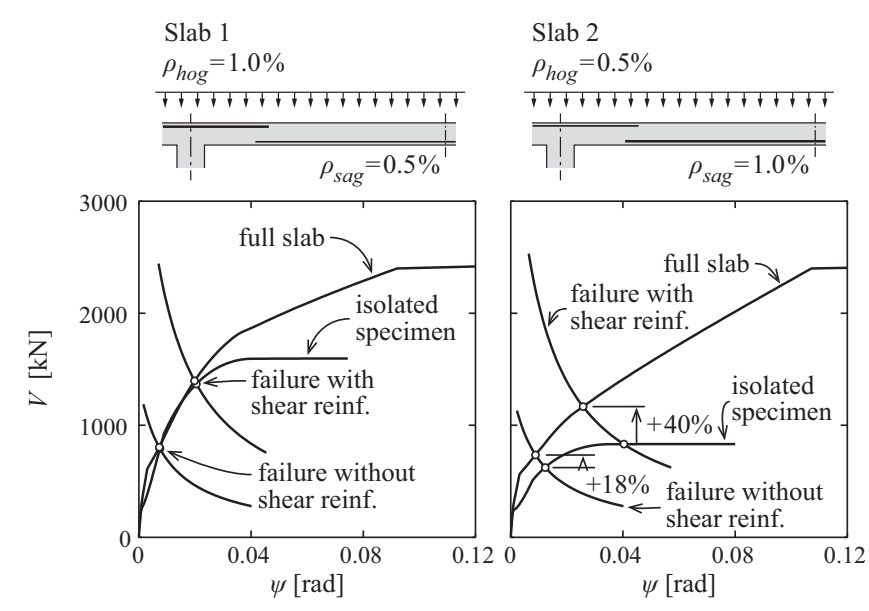

Fig. 8. Comparison of punching strengths of two slabs with equal plastic moment capacity but different support and span reinforcement distribution (parameters: refer to Fig. 7).

actual shear slenderness $r_{s} / d$ at that load level (Fig. 7(a)). For load levels where the shear slenderness of a continuous slab is smaller than the size of the isolated specimen, the rotation is also lower. It is also evident that the ultimate flexural strength of a continuous slab is higher than that of an isolated specimen due to the contribution of sagging yield lines in the failure mechanism (Fig. 7(c)). However, the necessary deformations of the slab in order to fully develop the yield lines are larger for the sagging reinforcement than for the hogging reinforcement. After reaching the flexural strength of a corresponding isolated specimen, the load on a continuous slab will continue to increase due to elastic activation of sagging reinforcement. Compared to the first phase, the stiffness of the slab is significantly reduced. However, in a wide range of practical cases, punching occurs at loads below the flexural strength of an isolated specimen. The failure criteria of CSCT [3] (Eq. (1)) for punching of slabs without shear reinforcement around columns with diameters of $c=d$ and $c=4 \cdot d$ are shown in Fig. 7(b) as examples. It can be seen that in these cases, the strength and the deformation capacity of an isolated specimen are very similar to the behavior of a continuous slab.

On the other hand, in the case of slabs with very low amount of hogging reinforcement, neglecting the influence of sagging reinforcement can lead to a significant underestimate of the punching strength. Fig. 8 shows an example of two slabs with equal yield line capacities $V_{\text {flex,yl }}$. In the case of slab 1, the flexural reinforcement is placed according to an elastic calculation (leading to relatively high hogging moments), thus the amount of hogging reinforcement is chosen as twice the amount of sagging reinforcement in mid-span. Slab 2 is designed assuming significant plastic moment redistribution, with twice less hogging reinforcement on the support than sagging reinforcement in the span. It can be seen that the prediction of punching strength of the isolated element corresponds reasonably well to the strength of the continuous slab in the first case. In the case of the second slab, the flexural stiffness and therefore the punching strength are underestimated by the analysis based on the isolated element. The difference is even more significant for slabs with shear reinforcement (calculated with $k_{\text {sys }}=2.8$ $[4,9])$. The isolated specimen representing only the hogging moment area may reach its flexural limit at a load level lower than the punching strength of a continuous slab. This kind of failure has been observed in punching tests of slabs with shear reinforcement even when using high flexural reinforcement ratios [35]. Stein et al. [36] argued that the flexural capacity of a specimen should be chosen at least $70 \%$ higher than the predicted punching strength. However, this would lead to unrealistically high flexural reinforcement ratios for slabs with large amounts of highly efficient shear reinforcement, and lead to misleading conclusions about the necessary amount of flexural reinforcement in column regions. The current analysis demonstrates that the distinction between a punching shear and flexural failure cannot be made only based on isolated specimens as suggested by [36].

\subsection{Influence of compressive membrane action}

Compressive in-plane forces delay the cracking of reinforced concrete in bending and stiffen the moment-curvature response of a cracked cross-section. The compression may result from prestressing [11] or from restrained lateral expansion due to external rigid elements (like shear walls) or the rigidity of the surrounding slab portion. The numerical model allows analyzing all these cases by varying the boundary conditions of the axisymmetric slab.

Fig. 9(b) shows load-rotation curves for different boundary conditions. Curves 1 and 2 represent an isolated slab and a continuous slab with the influence of membrane effect neglected (Fig. 7(b)). Points A and B represent the formation of the flexural mechanism for the slabs (Fig. 7(c)). The distribution of internal forces and deformations at point B is shown in Fig. 10(a).

Curve 3 in Fig. 9(b) shows the load-rotation response of a selfconfined flat slab (free to dilate, no in-plane force applied at the outer edge). In this case, the compressive membrane force in the center part of the slab results from the tangential tensile forces
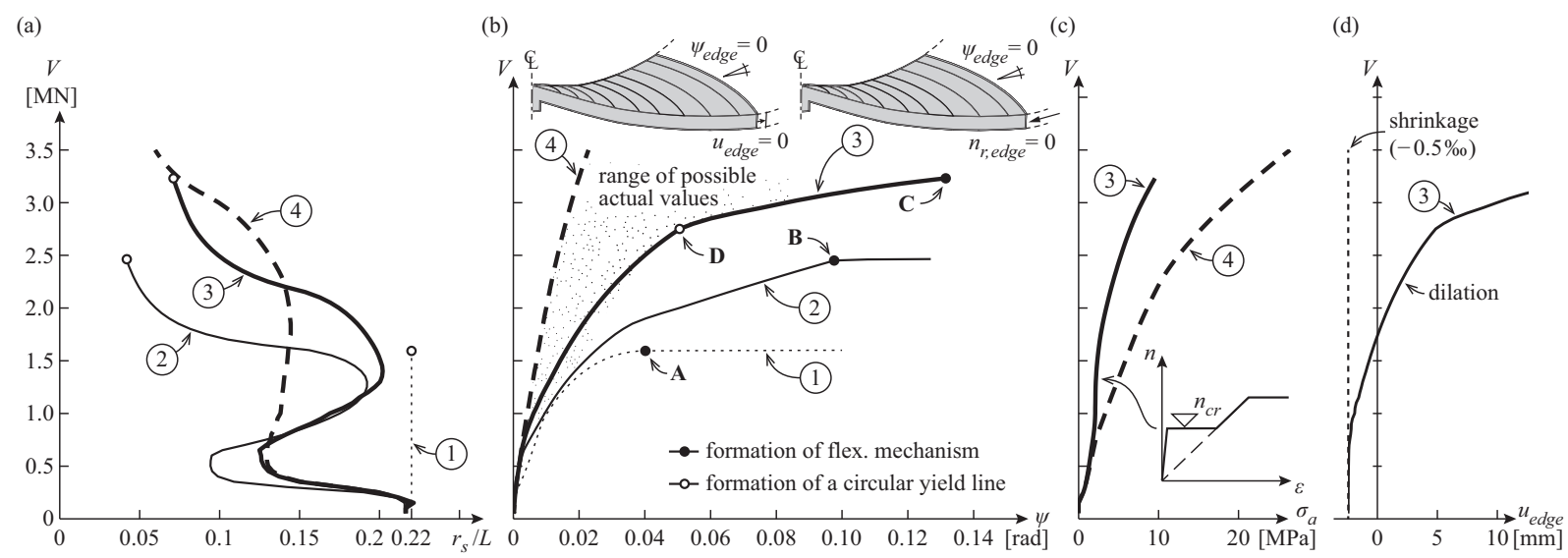

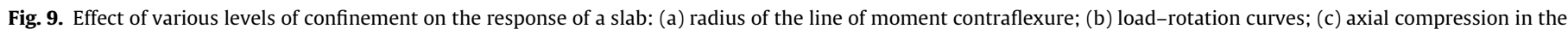
center of the slab; (d) dilation of the edge (parameters: refer to Fig. 7). 
(a)

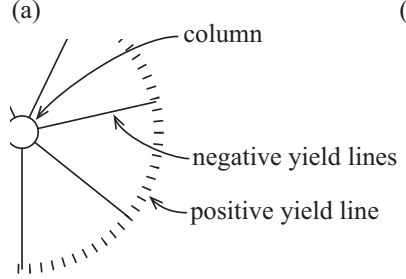

(b)

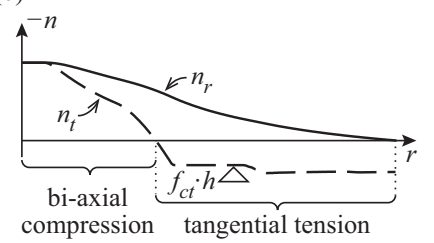

tangential strength increase
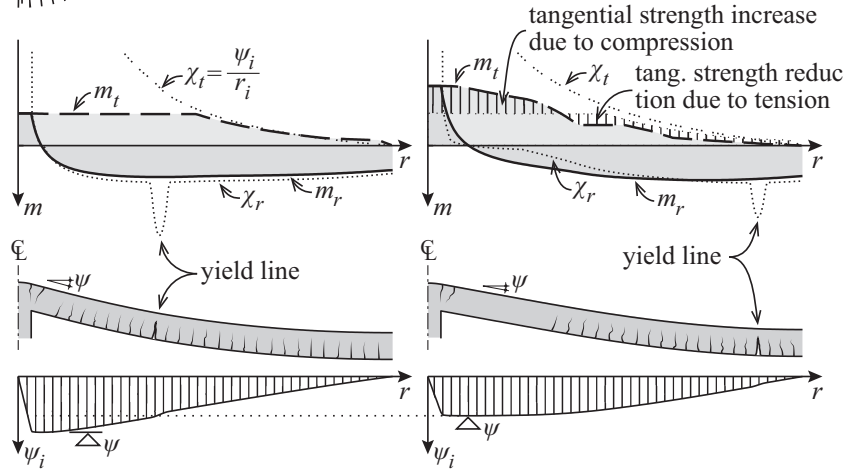

Fig. 10. In-plane forces $(n)$, bending moments $(m)$, curvatures $(\chi)$ and rotations $(\psi)$ at the formation of a circular positive yield line: (a) without considering membrane forces (point B in Fig. 9(b)); (b) with considering membrane forces, no external confinement (point D in Fig. 9(b)) (parameters: $L=5 \mathrm{~m} ; h=250 \mathrm{~mm} ; d=210 \mathrm{~mm}$; $\left.c=350 \mathrm{~mm} ; f_{c}=35 \mathrm{MPa} ; f_{s}=550 \mathrm{MPa} ; \beta=0.6 ; \rho_{\text {hog }}=1.0 \% ; \rho_{\text {sag }}=1.0 \%\right)$.

in the outer portion of the slab (the tension ring in Fig. 1(e)). The flexural limit of the slab is reached when a full yield line mechanism (Fig. 7(c)) forms (point C). This occurs at both higher load and larger rotation than in the case of curve 2 due to the increased flexural capacity and curvature at yielding of a reinforced concrete slab (Fig. 4(d)). The stiffness of the response is also significantly higher up to the point $\mathrm{D}$, which corresponds to the formation of a circular yield line due to yielding of radial sagging reinforcement. The distribution of internal forces and deformations at this point are shown in Fig. 10(b). The yield line appears further from the column than in the case of curve 2 (point B) (Fig. 10(a)) because of the radial compression in the region closer to the column. The formation of this yield line does not produce a flexural mechanism because the radial hogging yield lines are not yet formed inside the circular one. The significantly reduced rotation at point $\mathrm{D}$ on curve 3 compared to the point B on curve 2 is explained by the presence of a region in the slab which is under radial compression that is high enough to prevent the cracking of concrete, therefore reducing the maximum rotation.

Fig. 9(c) shows the magnitude of the radial compressive stress in the center of the slab. It depends on the load level and the consequent deformation of the slab as well as the axial stiffness of the tension ring. Hence, the portion of the curve 3 in Fig. 9(c) with constant compression stress corresponds to the cracking plateau of the axial force-deformation diagram of the slab (see the insert in the diagram).

Curve 4 in Fig. 9(b) shows the load-rotation response of a perfectly confined slab. Dilation is not allowed at the edges and therefore significant compressive forces are induced which increase towards the center of the slab. Unlike in the case of prestressed slabs where the normal force in the slab can be considered independent of the load, the compressive stress in the center of a perfectly confined slab increases with a rising load level and rotation (Fig. 9(c)). If concrete softening for large compressive strains was considered, the load would start decreasing because of the decreasing moment capacity under high axial compression. However, in the current analysis, this effect is neglected because of the bi-axial state of compression in the center of the slab (refer to Appendix A for additional details). Geometrical second order effects (Fig. 3(b)) are also not considered in this analysis. These effects would start decreasing the flexural strength at very large deflections (refer to Fig. 3 and [22]).

The dilation of an actual non-prestressed slab will often be restricted to some extent by structural elements such as walls, stiff columns or edge beams, inducing a compressive axial force at the edge of the slab. Eccentric compression (as prestressing) can lead to even higher stiffness (lower rotation for the same level of load) than the response of a perfectly confined slab [11]. It should be noted that shrinkage of the slab may reduce that force. In the case when the lateral shrinkage of the slab is larger than its lateral expansion due to the dilation caused by cracking, the restraining force at the edge of the slab (by adjacent stiff structural elements) may lead to the development of tensile membrane forces. This reduces the efficiency of the compressive membrane action (the actual response tends to curve 2 of Fig. 9(b)). The influence of this phenomenon is illustrated in Fig. 9(d), where the dilation of a selfconfined slab is compared to the corresponding displacement at its edge due to a shrinkage strain of $0.5 \%$. For low levels of load, the effect of shrinkage exceeds the effect of dilation, thus potentially reducing the compressive membrane forces. For higher levels of rotation, the shrinkage strains will be compensated by the dilation of cracked concrete and compressive membrane forces may again appear. In these cases curve 3 (no external confinement) provides a safe estimate of the actual behavior, which should develop in between curves 3 and 4 (fully-confined slab). However, in many cases, a self-confined model with zero axial force at the edge of the slab can be regarded as a lower bound of the confinement effect for actual flat slabs.

\section{Comparison of the numerical model to experiments}

In the following, the numerical model is applied to predict the deformations of specimens in some unconventional punching tests reported in the literature [17-19]. Only the tests on slabs thicker than $100 \mathrm{~mm}$ are considered as the punching shear phenomenon is known to exhibit significant size effect and the results of experiments on very thin elements are difficult to extrapolate to a realistic scale (also, small variations in placing of reinforcement may lead to significant strength variations). Tests on isolated slabs with confining elements (like [31]) are also excluded from the analysis because the stiffness of a steel confinement ring is typically much smaller than the stiffness of a reinforced concrete tension ring in a continuous slab. Therefore, the arising axial forces are low and do not influence the response of the slab in a significant manner. The contribution of such elements can mainly be seen as related to an increase of the flexural strength.

The parameters used for modeling the slabs are shown in Table 1. The failure criterion of CSCT (Eq. (1)) is applied to predict the punching capacity. The failure criterion may be modified to include the beneficial influence of the axial compressive forces acting on the control perimeter [11], which can also be obtained from the numerical analysis (Fig. 9(c)). The capacity obtained in this manner is also presented in Table 2 for the applicable cases. For comparison purposes, the slabs are also modeled as conventional isolated specimens, where the size of the specimen $r_{s}$ is chosen to correspond to the edge of the elastic hogging moment area. Fig. 11 shows the sketches of the test configurations and loaddeformation curves for the different models.

Choi and Kim [19] reported on three tests on $4.2 \times 4.2 \mathrm{~m}$ slabs. The slabs were loaded in 16 points and supported by a column in the center. The load was applied in three loading steps, on each step in a cyclic manner $(\Delta V=100 \mathrm{kN})$. The rotation of the edges was partially restrained by steel columns connected by steel ties 
Table 1

Modeling parameters of tests of Choi and Kim [19], Chana and Desai [18] and Ladner et al. [17].

\begin{tabular}{|c|c|c|c|c|c|c|c|c|c|c|}
\hline Ref. & Test & $f_{c}(\mathrm{MPa})$ & $f_{s}(\mathrm{MPa})$ & $A_{s w}\left(\mathrm{~mm}^{2}\right)$ & $\rho_{\text {hog }}(\%)$ & $\rho_{\text {sag }}(\%)$ & $h(d)(\mathrm{mm})$ & $r_{c}(\mathrm{~mm})$ & $r_{\text {slab }}\left(r_{s}\right)(\mathrm{mm})$ & Edge conditions \\
\hline \multirow[t]{3}{*}{ [19] } & MRA & 37.0 & 404 & - & 1.059 & 0.306 & & & & $\psi_{\text {edge }}(\mathrm{rad})=6.67 \cdot 10^{6} \cdot V(\mathrm{MN})$ \\
\hline & MRB & 30.5 & & & 0.832 & 0.433 & 152 & 178 & 2100 & \\
\hline & MRC & 34.6 & & & 0.575 & 0.573 & (121) & & $(1500)$ & $n_{R}=0$ \\
\hline \multirow[t]{5}{*}{ [18] } & FPS1 & 21.4 & $500^{\mathrm{a}}$ & - & & & & & & \\
\hline & FPS2 & 27.4 & & 942 & & & & & & $m_{R}=0$ \\
\hline & FPS3 & 27.2 & & 402 & 0.85 & 0.85 & 250 & 200 & 4500 & $n_{R}=0$ \\
\hline & FPS4 & 30.7 & & 1257 & $0.27^{\mathrm{b}}$ & $0.55^{\mathrm{b}}$ & $(210)$ & & $(1320)$ & $w_{\text {edge }}=0$ \\
\hline & FPS5 & 25.8 & & 1570 & & & & & & \\
\hline \multirow[t]{4}{*}{ [17] } & C6 & 44.4 & 550 & - & & & & 50 & & \\
\hline & C7 & & & & & & 110 & 120 & 1680 & $m_{R}=0$ \\
\hline & C10 & & & & 1.80 & 0.94 & (80) & 100 & (528) & $n_{R}=0$ \\
\hline & C11 & & & & & & & 160 & & \\
\hline
\end{tabular}

a Nominal value.

b Outside of $r=1925 \mathrm{~mm}$.

Table 2

Comparison between the test results and predictions based on isolated elements and continuous slabs.

\begin{tabular}{|c|c|c|c|c|c|}
\hline Ref. & Test & $V_{R, \text { test }} / b_{0} d \sqrt{ } f_{c}(\sqrt{ } \mathrm{MPa})$ & $V_{R, \text { test }} / V_{R}$ (isol.) & $V_{R, \text { test }} / V_{R}$ (cont.) & $V_{R, \text { test }} / V_{R}$ (cont., mod. criterion) \\
\hline \multirow[t]{3}{*}{ [19] } & MRA & $0.345^{\mathrm{a}}$ & $1.06^{\mathrm{a}}$ & $0.80^{\mathrm{a}}$ & $0.76^{\mathrm{a}}$ \\
\hline & MRB & $0.327^{\mathrm{a}}$ & $1.07^{\mathrm{a}}$ & $0.77^{\mathrm{a}}$ & $0.73^{\mathrm{a}}$ \\
\hline & MRC & $0.335^{\mathrm{a}}$ & $1.36^{\mathrm{a}}$ & $0.82^{\mathrm{a}}$ & $0.77^{\mathrm{a}}$ \\
\hline \multirow[t]{5}{*}{ [18] } & FPS1 & 0.558 & 1.36 & 0.94 & - \\
\hline & FPS2 & 0.608 & 1.29 & 0.99 & - \\
\hline & FPS3 & 0.716 & 1.68 & 1.21 & - \\
\hline & FPS4 & 0.771 & 1.61 & 1.25 & - \\
\hline & FPS5 & 0.805 & 1.50 & 1.26 & - \\
\hline \multirow[t]{4}{*}{ [17] } & C6 & 0.574 & 1.18 & 1.03 & 0.94 \\
\hline & C7 & 0.658 & 1.27 & 1.15 & 1.07 \\
\hline & $\mathrm{C} 10$ & 0.632 & 1.28 & 1.14 & 1.08 \\
\hline & C11 & 0.690 & 1.46 & 1.33 & 1.26 \\
\hline Mean & & & 1.41 & 1.14 & 1.09 \\
\hline $\mathrm{COV}$ & & & $12 \%$ & $12 \%$ & $12 \%$ \\
\hline
\end{tabular}

a Cyclic tests, not included in the calculation of mean and coefficient of variation.

on top (Fig. 10(a)). The forces in the ties were measured which allowed calculating the edge moments. The rotations at the edges were also measured. The test campaign focused on studying the effect of moment redistribution in continuous slabs. The slabs were designed with similar flexural capacities but different ratios between the amounts of sagging and hogging reinforcement (refer to Table 1 for details). Analyses based on isolated specimens only take into account the influence of hogging reinforcement and therefore lead to decreasing punching shear strength for decreasing amount of tensile reinforcement at the column region. However, the measured failure loads were similar in all the tests contrary to the predictions of many empirical formulas that were calibrated on isolated test specimens [1]. This effect can be correctly predicted by the numerical model accounting for the midspan reinforcement ( $\rho_{\text {sag }}$; refer to Table 1$)$. The failure loads are slightly overestimated by the model (Table 2), possibly due to the cyclic loading pattern (low cycle fatigue), which is not considered in the failure criterion. However, the model is able to predict that the increase of the sagging reinforcement ratio is sufficient to compensate for the decreased hogging reinforcement ratio, so that the load-deformation responses of the specimens are similar (Fig. 11(a)).

Chana and Desai [18] tested five $9 \times 9 \mathrm{~m}$ full-size slabs; four of which were equipped with shear reinforcement. The slabs were supported on a column in the center and on a linear support at the perimeter (Fig. 11(b)). The perimeter support allowed both rotation and horizontal displacement. The load was applied in eight points placed at a radius of $1.2 \mathrm{~m}$ from the center. All the slabs had similar concrete strengths, the other parameters were identical. Fig. 11(b) shows the predicted load-deflection response from the numerical model compared to the measured deflections. A load-deflection curve for the corresponding isolated element is also shown. It can be seen that the continuous model predicts the deflections correctly, whereas the deflections of the isolated specimens exceed the measured values several times. Due to this, the punching loads are significantly underestimated by the isolated model (Table 2), fitting reasonably well with the continuous one.

Ladner et al. [17] performed tests on a $7.2 \times 7.2 \mathrm{~m}$ slab supported on 16 different size columns. The slab was loaded with uniform pressure to the failure of a slab-column connection. After each failure, the slab was repaired and the loading was continued, until all the connections had failed in punching. In addition to the reaction force at each column, the deflection of the slab was measured at different points under the slab. Fig. 11(c) compares the measured deflections around the interior columns on the strong and on the weak axis to the curves predicted by the numerical model. Also presented are the failure criterion of CSCT and the load-rotation curves of corresponding isolated elements [3]. It can be seen that the numerical model predicts the deflections very well, whereas the calculations that are based on isolated elements always underestimate the stiffness. Due to the underestimate of 
(a)
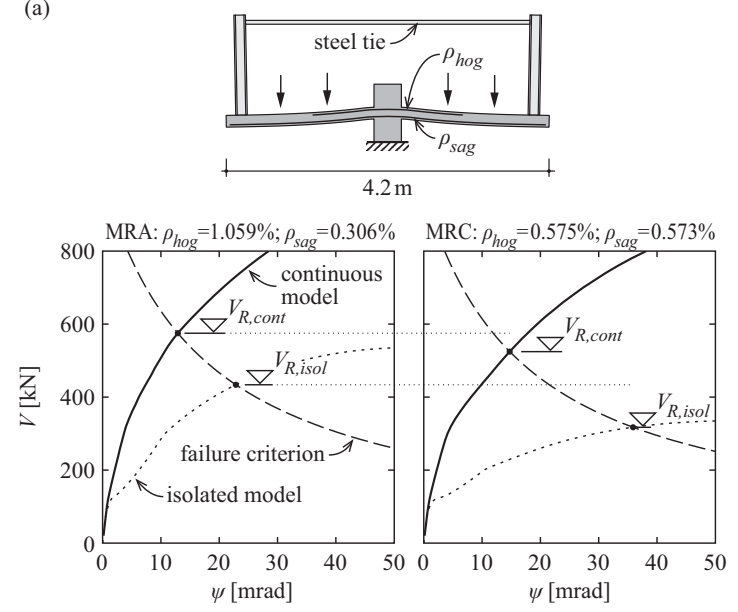

(b)
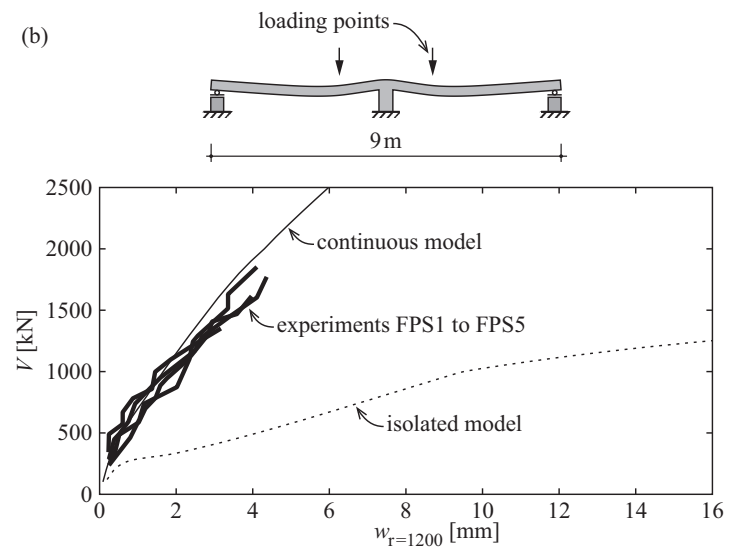

(c)
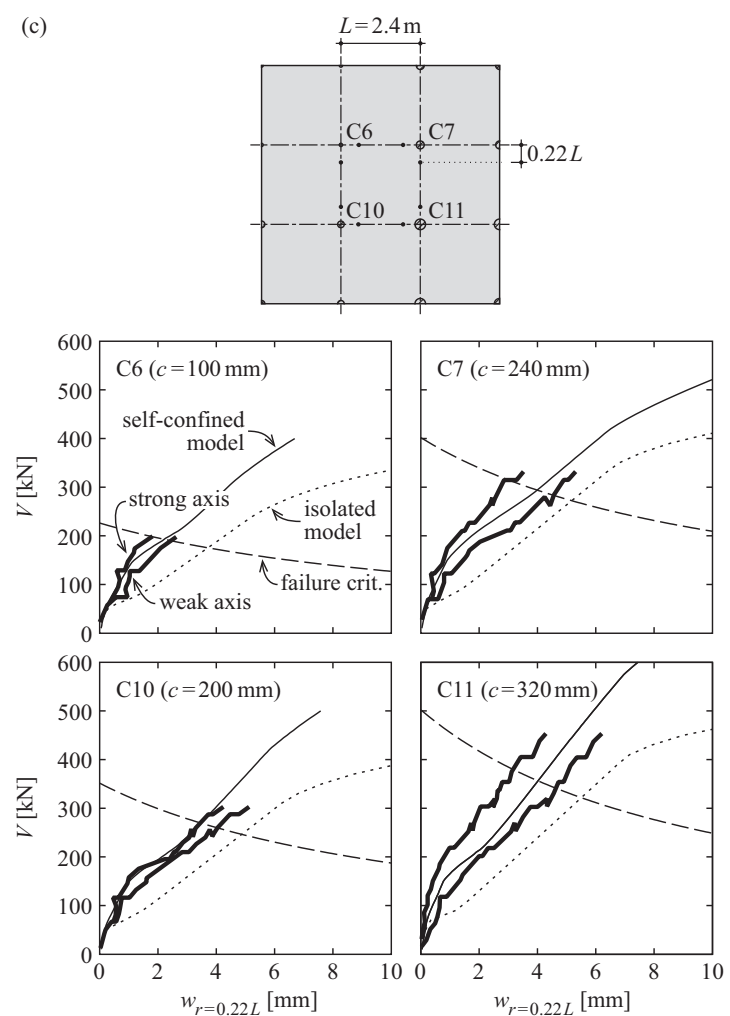

Fig. 11. Comparison of the numerical model to the experimental results: (a) loadrotation curves of specimens MRA and MRC of Choi and Kim [19]; (b) loaddeflection curves of specimens of Chana and Desai [18]; (c) load-deflection curves of Ladner et al. [17] experiment. the deflections, the predictions are more conservative for the isolated model (Table 2).

\section{Parametric analysis}

In the previous sections, it has been demonstrated how the slab continuity and compressive membrane action influence the punching capacity of an actual flat slab. In the current section, results of a parametric study to analyze the influence of several factors on the prediction of the punching capacity are presented. A study based on CSCT on the influence of more parameters (including the size effect) can be found elsewhere [3]. The slab is assumed to be self-confined. The punching capacities are found at the intersection of a load-rotation curve $(V-\psi)$ with a failure criterion (as explained in [3] and Section 1.1 of the present paper), calculated using the following approaches:

- V- $\psi$ according to the Model Code 2010 [4], failure criterion from Eq. (1);

- $V-\psi$ of an isolated element according to the 4-linear model [3], failure criterion from Eq. (1);

$-V-\psi$ of the presented continuous model taking into account the effect of moment redistribution but neglecting the influence of in-plane forces, failure criterion from Eq. (1);

$-V-\psi$ of the presented continuous model taking into account both the effect of moment redistribution and the membrane action, failure criterion from Eq. (1);

$-V-\psi$ of the presented continuous model taking into account both the effect of moment redistribution and the membrane action, failure criterion from Eq. (1) with a modified rotation $\psi^{\prime}[11]$.

Fig. 12(a) shows the influence of slab slenderness $L / d$ on the punching capacity. Although the slenderness effect is not taken into account in many codes of practice [1,2], it is well known [33] and can be successfully accounted for by using CSCT [3] or the Model Code 2010 [4]. All the studied methods show a similar influence of the slab slenderness on the punching strength. The effect can be seen to be more important for slabs with shear reinforcement.

Fig. 12(b) shows the influence of the hogging reinforcement ratio on the punching strength. The presented curves are for slabs without and with shear reinforcement (maximum punching shear resistance due to concrete crushing $\left(k_{\text {sys }}=2.8\right)$ ). Two possible design cases are investigated. First, a case where the amount of sagging reinforcement equals to the amount of hogging reinforcement (plastic design) and a second case where the amount of sagging reinforcement is half of the amount of hogging reinforcement (corresponding to a typical elastic design). The ratio of hogging reinforcement is known to have an important influence on the stiffness and punching strength of isolated test specimens and the influence is considered in many codes of practice $[1,4]$. However, other design codes [2] neglect its influence. The present analysis shows that in the case of low hogging reinforcement ratios, the flexural and axial stiffness of the surrounding portion of the slab might be able to stiffen the load-rotation response in a considerable manner and therefore reduce the influence of hogging reinforcement ratio on the punching capacity of continuous slabs.

The influence of the amount of sagging reinforcement on punching strength is currently not included in design codes $[1,2,4]$. However, comparing the curves corresponding to plastic and elastic designs in Fig. 12(b) indicates this factor may nevertheless have an importance. In the presented example, doubling the amount of sagging reinforcement led to a punching strength increase of approximately $5 \%$ for slabs without shear reinforce- 
ment and up to $10 \%$ for slabs with shear reinforcement. This increase may be useful, for example in the assessment of existing structures.

Long-term behavior of flat slabs is influenced by creep behavior of concrete that will lead to an increase of slab rotation and potential decrease of the punching strength (as follows from Eq. (1)), at least in the case when the increase of strength of concrete in time is not taken into account. The presented approach can be used in a simplified manner to model the effect of creep by using a reduced value of modulus of elasticity of concrete $E_{c} /(1+\phi)$ (where $\phi$ refers to the creep coefficient and low variations of concrete stresses are assumed during the creep process) for calculating the deformations due to long-term loads. In Fig. 12(c), the predicted punching resistances calculated with $E_{c}$ are compared to predictions obtained with $50 \% E_{c}$ (to account for a reduced influence of creep effects in cases where the ratio between permanent and maximum loads is lower than one). The reduced stiffness is observed to reduce the punching strength similarly for both isolated slabs (up to $4 \%$ ) as well as for continuous slabs with no membrane effect (up to 5\%) and self-confined slabs (up to $7 \%$ ). Therefore, it seems that tests on isolated specimens could be suitable for further studies on the influence of creep on punching strength of flat slabs.

The stiffness of the tangential tension ring that provides the confinement for the hogging moment area in self-confined slabs is largely provided by the contribution of uncracked concrete (Fig. 10(b)). It follows that the value of the tensile strength of concrete $f_{c t}$ has a significant influence on the predicted punching strength of continuous slabs. Fig. 12(d) shows the influence of reducing the value of $f_{c t}$ two times. The notable influence of this parameter on the punching strength indicates that the design value of the tensile strength of concrete has to be chosen carefully for such analysis. However, depending on the type of analysis, neglecting its contribution could be overly prudent in the opinion of the authors and a safe estimate of its value (for instance, $f_{c t k, 0.05}$ ) could be used for design purposes.

\section{Summary and conclusions}

In this paper, a numerical method is presented for determining the load-deformation response of axisymmetric slabs. This model allows quantifying the influence of moment redistribution and the development of compressive membrane action in a continuous flat slab around interior columns. The model was validated by comparing its predictions to the results of punching tests with unconventional edge conditions. In combination with the failure criterion of the Critical Shear Crack Theory, the presented method is able to predict the punching strength of interior columns in continuous flat slabs.

The main conclusions are:

1. Flexural behavior may be different in actual flat slabs than in isolated test specimens. Therefore, punching tests on such specimens may not always correctly represent the strength of actual slabs, especially in the case of large columns and the presence of shear reinforcement.

2. The flexural capacity of a continuous slab is higher than of an isolated element for the same amount of hogging reinforcement. The stiffness of the load-deformation response also normally increases due to a reduction of the shear slenderness and the influence of compressive membrane action. Nevertheless, these effects do not seem to be accounted for in the punching provisions of current design codes. (a)

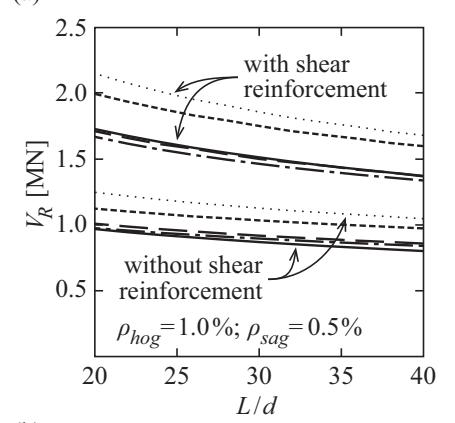
- MC2010
- - - - quadrilinear
- - moment redistribution only
moment redistribution and membrane action moment redistribution and membrane action, modified failure criterion

(b)
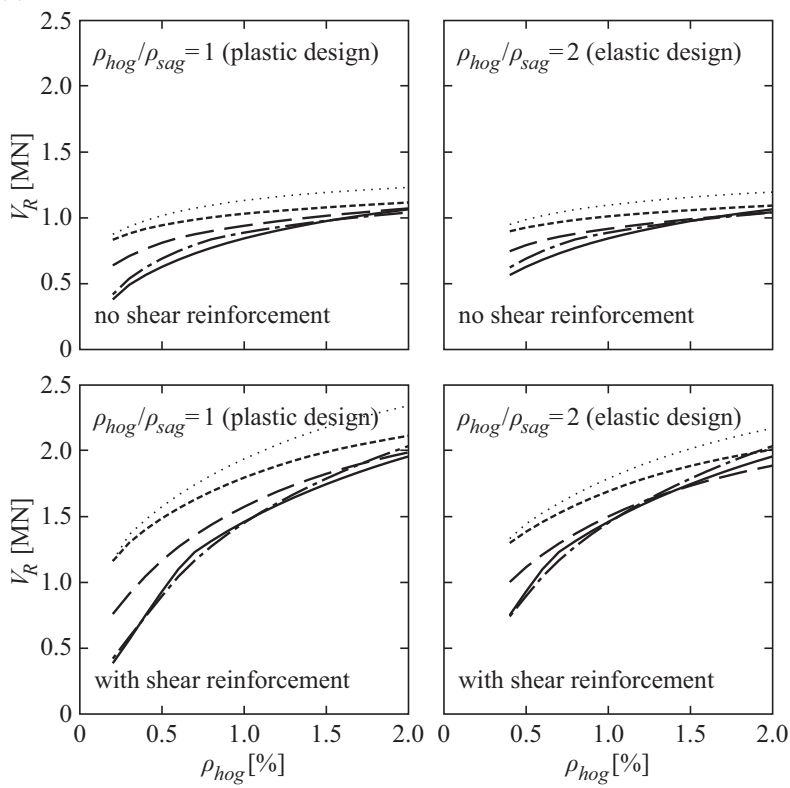

(c)

(d)
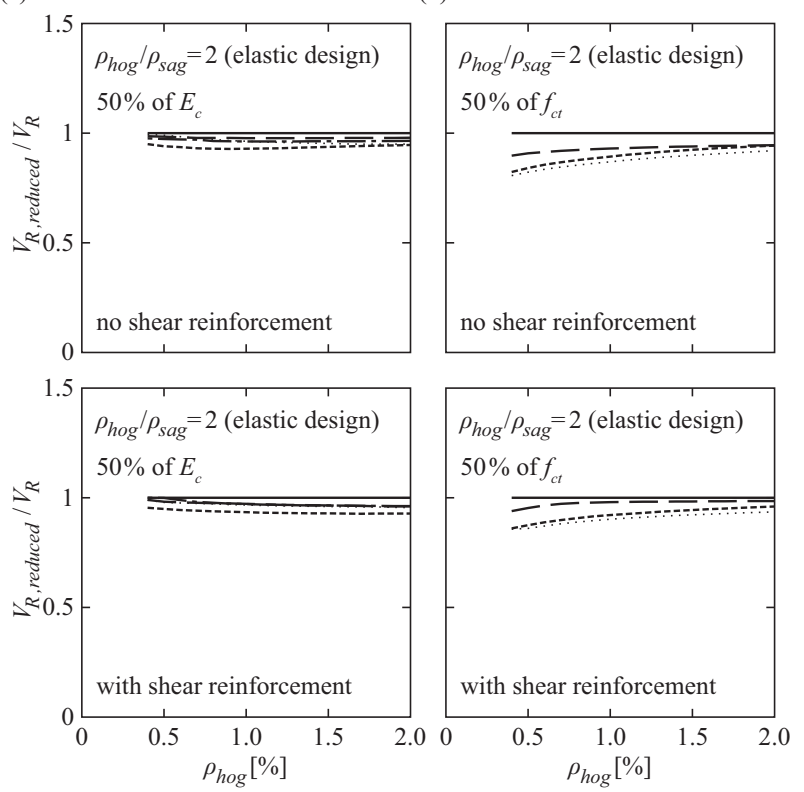

Fig. 12. Parametric study: (a) influence of slenderness; (b) influence of the hogging reinforcement ratio and the amount of sagging reinforcement, for slabs without shear reinforcement and for slabs with large amounts of double-headed stud shear reinforcement; (c) influence of reduced modulus of elasticity of concrete; (d) influence of reduced tensile strength of concrete (parameters: $L=7 \mathrm{~m} ; h=250 \mathrm{~mm}$; $\left.d=210 \mathrm{~mm} ; c=350 \mathrm{~mm} ; f_{c}=35 \mathrm{MPa} ; f_{s}=550 \mathrm{MPa} ; \beta=0.6 ; d_{g}=16 \mathrm{~mm}\right)$. 
3. The compressive membrane action may arise from the restraint against the expansion of the slab provided by stiff surrounding structural elements but also due to the restraint against the expansion of the hogging moment area provided by the inplane stiffness of the sagging moment area. This effect does not require any external confinement, is not sensitive to imposed deformations such as shrinkage and can therefore be considered as a lower bound of the behavior for actual continuous flat slabs.

4. Due to the effects described above, the deflections of a continuous flat slab are smaller than the ones of a corresponding isolated specimen. This leads to lower crack widths and potentially larger punching strength.

5. These aspects lead to potentially higher safety margins on the design for punching strength around interior columns of actual flat slabs than presumed in the current codes of practice as the provisions of those have been calibrated using tests on isolated specimens. Such increase in strength should be considered, particularly for the assessment of existing structures in order to avoid unnecessary strengthening.

6. The Model Code 2010 punching previsions that are based on a physical model can be adapted to take these effects into account. A numerical approach is presented in the current paper. Comparisons to test results confirm the pertinence of these aspects.

\section{Acknowledgments}

The work presented in this paper was funded by the Swiss National Science Foundation (project nr. 200021 137658). The authors would like express their sincere gratitude for the support received.

\section{Appendix A. Conversion of a regular-span continuous slab to an axisymmetric model}

The axisymmetric model is developed assuming several simplifications compared to an actual slab regarding the geometry and placement of the reinforcing bars.

Firstly, in the axisymmetric case, the deflection of the slab at its outer edge is considered constant along the whole edge. However, in the case of a continuous slab supported on a regular grid of columns, the deflection is smaller on the axes and larger in the middle of the fields (Fig. A.1(a)). Therefore, the choice of the radius for the continuous model that would predict correctly the deformations of the slab in the vicinity of the column is not as straightforward as in the case of the radius for an isolated element.

In this paper, the radius of the slab $r_{\text {slab }}$ has been chosen so that in the elastic uncracked phase, the axisymmetric continuous model has to yield the same radius of moment contraflexure $r_{s}$ of $0.22 \mathrm{~L}$ as an elastic analysis of a regular-span slab. This leads to $r_{\text {slab }} \cong 0.7 \mathrm{~L}$. The radius is larger than it would be based on purely geometrical considerations (the same contributive area, for instance) because of the overestimate of the tangential curvature and therefore the contribution of tangential moments in the outer part of the axisymmetric model. Compared to the sagging moment area of an actual slab, the tangential curvatures are larger in the numerical model and the radial stiffness is therefore overestimated. This can be compensated for by increasing the extent of the slab in the axisymmetric model. The distributed load on the slab is correspondingly decreased by a factor of $0.7^{2} \cdot \pi=1.54$ to yield an equal column reaction.

Secondly, in the axisymmetric model, the reinforcement is assumed to be laid in the radial and in the tangential directions. (a)
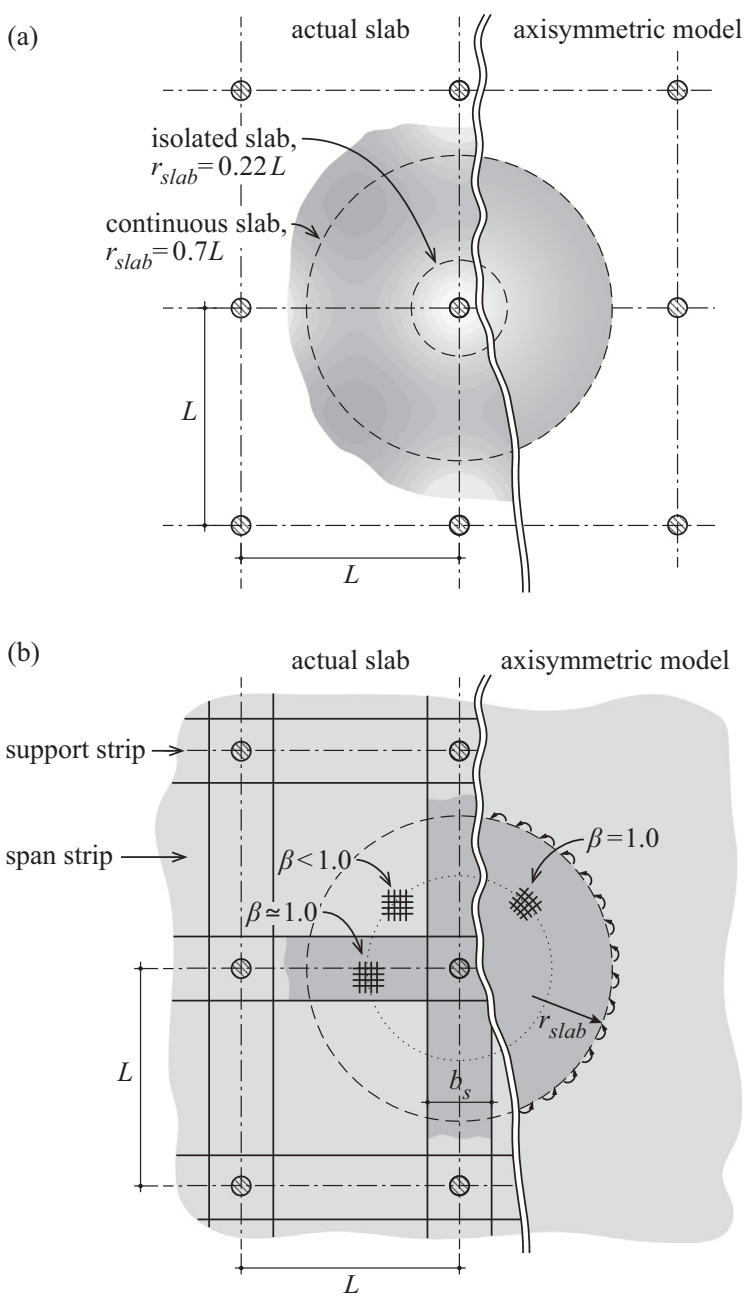

(c)

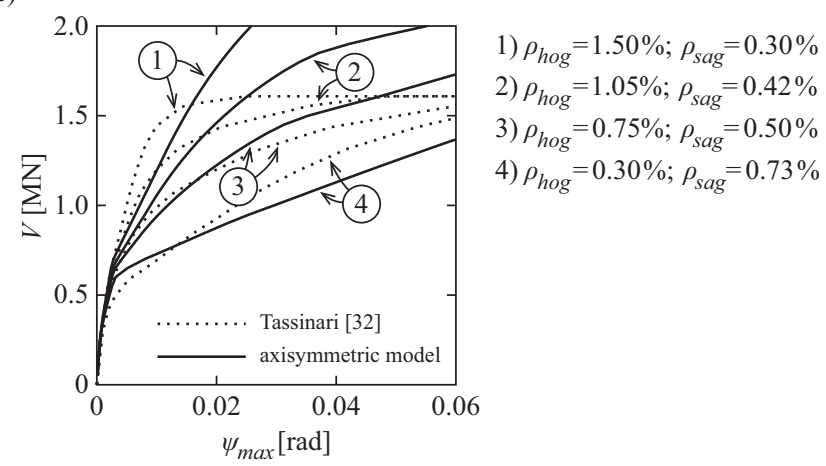

Fig. A.1. Conversion of an actual slab to an axisymmetric model: (a) comparison of slab deflections; (b) simplification of the reinforcement layout; (c) comparison with a non-linear parametric study by Tassinari [34].

In actual slabs, however, the reinforcement is placed orthogonally and may therefore cross the radial and the tangential planes at oblique angles. In these cases, the stiffness of the tension chord of the cross-section is reduced. This effect is taken into account in the multi-linear moment-curvature law with an efficiency factor $\beta$ that reduces the stiffness of a cracked cross-section (refer to Appendix B). For uniformly reinforced isolated test specimens, an average value of $\beta=0.6$ gives good results in comparison to the test results [3] and the same value has been used in the current research.

Thirdly, in the axisymmetric model, top and bottom reinforcement ratios are considered constant over the whole slab. However, 
in actual slabs, top reinforcement is usually concentrated in strong bands (support strips) between the supports (Fig. A.1(b)) and significantly lower amounts of flexural reinforcement are provided in the areas between these strips. This results in redistribution of internal forces and concentration of bending moments on the support strips due to the higher flexural stiffness of these strips after cracking.

When applying the present model for actual slabs, the influence of the distribution of hogging reinforcement can be taken into account analogously to the Model Code 2010 [4], where the width of the support strip $b_{s}$ for interior columns is defined as $75 \%$ of the width of the elastic hogging moment area $\left(1.5 \cdot r_{s}\right)$. As a practical rule, it is suggested that the sagging reinforcement ratio be also defined as an average ratio over the width of the column strip. This value may be higher than the geometrically weighted average over the whole sagging moment area. However, considering firstly the concentration of bending moments on the stiffer support strips and secondly, the higher $\beta$-factor of these strips compared to the span strips (as the reinforcement in the strong strips is placed parallel to the direction of principal moments (Fig. A.1(b)), this approach is believed to be reasonable and realistic. A comparison with numerical non-linear solutions [34] for square-spanned slabs with the reinforcement concentrated in strips shows a reasonable (possibly slightly prudent) agreement with the axisymmetric model (Fig. A.1(c)).

Thirdly, in the axisymmetric model, the reinforcement is assumed to be laid in the radial and in the tangential directions. In actual slabs, however, the reinforcement is placed orthogonally and is therefore crossing the radial and tangential planes often at oblique angles. In these cases, the stiffness of the tension chord in the cross-section is reduced. This effect is taken into account in the multi-linear moment-curvature law with an efficiency factor $\beta$ that reduces the stiffness of a cracked cross-section (refer to Appendix B). For uniformly reinforced isolated test specimens, an average value of $\beta=0.6$ gives good results in comparison to the test results [3] and the same value has been used in the current research.

\section{Appendix B. Multi-linear sectional analysis}

In this appendix, a simplified multi-linear relationship is developed between the internal forces acting on a cross section and its deformations. The internal forces considered are the bending moment $m$ and the axial force $n$, whereas the related deformations are curvature $\chi$ and dilation of the axis $\varepsilon$. The law is based on an approach used by Muttoni [3] and Clément et al. [11] but it is modified to describe the dilation of the axis and to approximate the response of a section under high tensile forces in a more suitable manner. The resulting curves and a comparison with a layered non-linear analysis are presented in Fig. 4(d) and (e).

A number of simplifications are made to ensure the continuity of the curves and to facilitate the use of the multi-linear law in the iterative calculations of the numerical model. The momentcurvature and the curvature-dilation relationships are assumed to consist of linear regimes, as shown in Fig. B.1(a)-(c) for some different levels of axial load:

- In the uncracked regime, the slope of the moment-curvature relationship is equal to the stiffness of a full concrete cross-section $E I_{0}$. The influence of the tension and compression reinforcement can be normally neglected (Fig. B.2(a)). This regime describes the response between zero moment and cracking moment $\left(m_{c r}\right)$. Cracking moment is defined depending on the level axial force as a bending moment that induces a tensile force equal to $f_{c t}$ in the outermost tension fiber of the cross-section [11]. Compressive axial force increases the cracking moment, whereas tensile axial force decreases it. In the presence of high tensile forces, the tensile stress in concrete may exceed the tensile strength in the whole cross-section $\left(n>n_{c r}\right)$. In this case, the cross-section is cracked in tension at zero bending moment and the uncracked regime does not apply (Fig. B.1(c)).

The dilation of the axis $\varepsilon$ in the uncracked regime mainly depends on the deformation due to the axial force $\varepsilon_{0}$ (Fig. B.3(a)).

- If the applied moment exceeds the cracking moment, a cracked regime applies. In this regime, the $m-\chi$ relationship is assumed to be linear with a slope equal to the stiffness of a fully cracked cross-section $\left(\beta E I_{1}\right)$ that is composed of the compression zone and the reinforcing bars (Fig. B.2(b)) multiplied by an efficiency factor $\beta$. The efficiency factor takes into account the orthogonal placement of the reinforcing bars, which is not equivalent with the polar placement that is assumed in the axisymmetric model. A suitable value of $\beta$ is shown to be 0.6 [3]. The contribution of concrete in tension is neglected when calculating $E I_{1}$. However, the contribution of the tensile stresses in the concrete around steel rebars due to bond between the reinforcing bars and concrete are taken into account with a tension stiffening factor [3]:

$$
\Delta \chi_{T S}=\frac{f_{c t m}}{\rho \cdot \beta \cdot E_{s}} \cdot \frac{1}{6 \cdot h}
$$

(a)
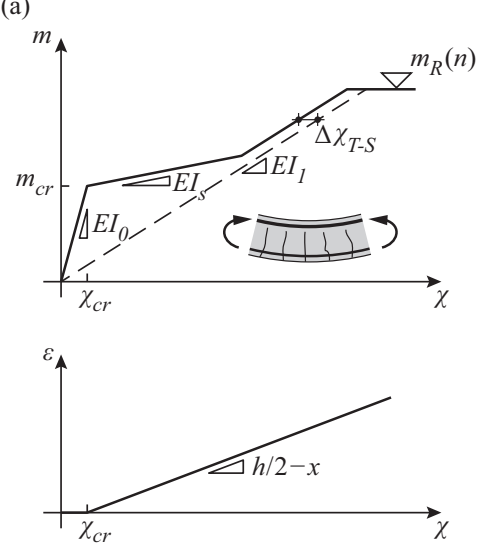

(b)
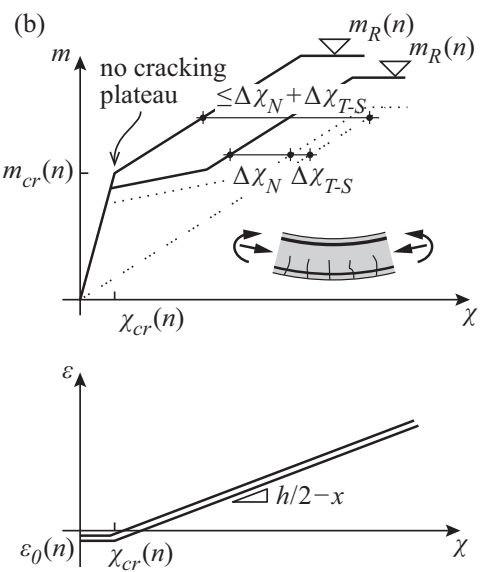

(c)
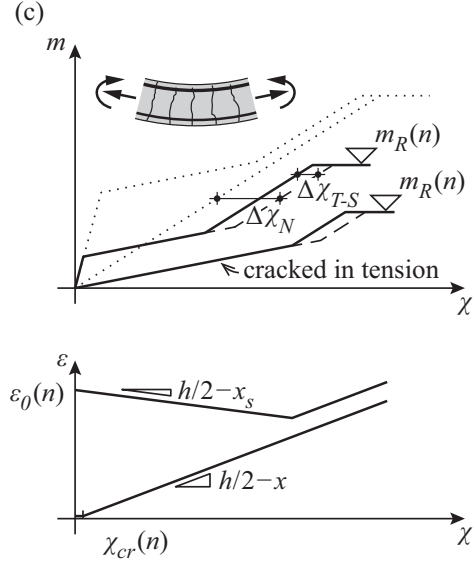

Fig. B.1. Moment-curvature and moment-dilation relationships for different levels of axial load: (a) no axial force; (b) axial compression; (c) axial tension. 
(a)
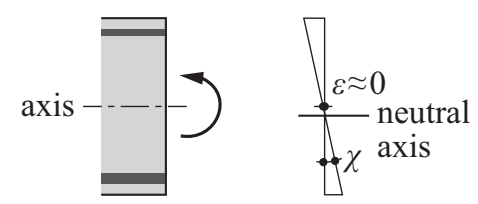

(b)
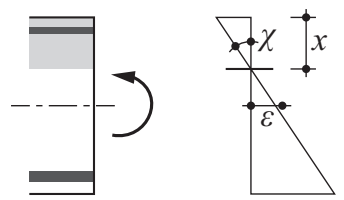

(c)

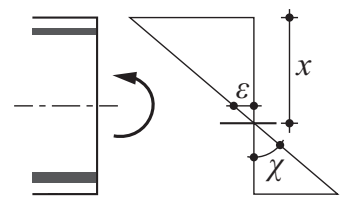

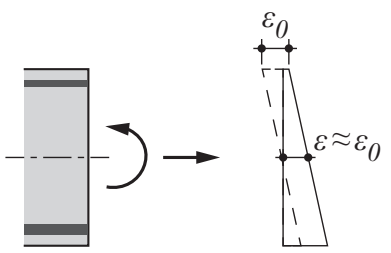
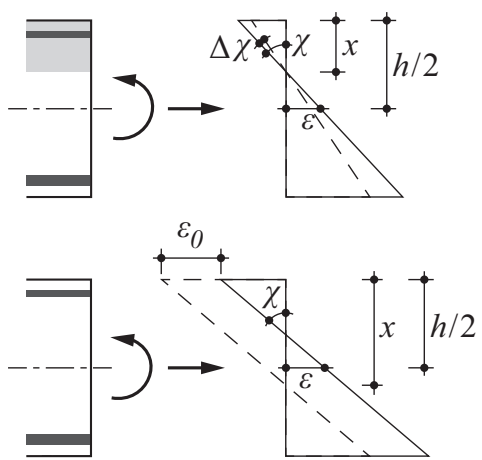

Fig. B.2. Sectional analysis: (a) uncracked regime; (b) partially cracked regime; (c) fully cracked regime.

(a)

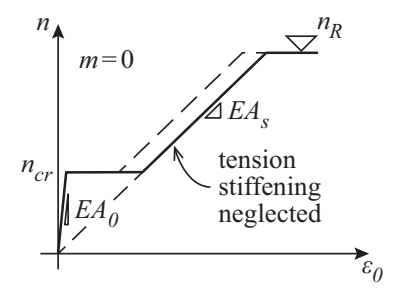

(b)

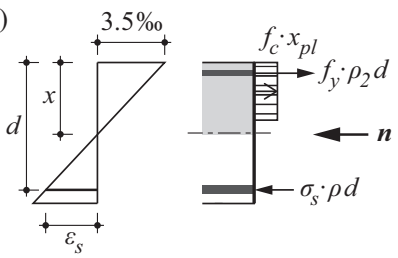

Fig. B.3. (a) Axial force-dilation relationship with no bending moment; (b) strains and forces at the cross-section in the case of high compressive axial forces; (e) adapted axial load-moment capacity relationship.

Applying an axial force on the cross-section affects the height of the compression zone. As a simplification, however, this change is neglected. The influence of the axial forces is taken into account by modifying the curvature due to different stiffness of the tension tie and the compression chord (Fig. B.2(b)). The change of the curvature due to the axial load is [11]:

$\Delta \chi_{N}=\frac{-n}{(d-x / 3)^{2}} \cdot\left(\frac{h / 2-x / 3}{\rho \cdot d \cdot E_{s} \cdot \beta}-\frac{2 \cdot(d-h / 2)}{\chi \cdot E_{c}}\right)$

The total contribution of the aforementioned effects is thus:

$\Delta \chi=\Delta \chi_{T-S}+\Delta \chi_{N}$

The contribution of tension stiffening $\Delta \chi_{T-S}$ is always positive (decreasing the curvature). The contribution of the normal force $\Delta \chi_{N}$ can be positive (decreasing the curvature) in the case of compression (Fig. B.1(b)) or negative (increasing the curvature) in the case of tensile axial forces (Fig. B.1(c)). In the case of high compres- sive forces, $\Delta \chi$ may be so large that the curvature at cracking $\chi_{c r}$ is less in the cracked regime than in the uncracked regime. In this case, the value of $\Delta \chi$ is limited to yield the same in the $\chi_{c r}$ cracked regime as in the uncracked regime [11] (Fig. B.1(b)).

At the onset of cracking, the dilation of an element is known to increase abruptly while the cracks are formed. After the initial formation phase, the cracks will start growing and the increase of dilation will become more stable. In the current analysis, this phenomenon is neglected and the dilation in the cracked regime is assumed to increase linearly from the dilation in the uncracked regime $\varepsilon_{0}$ (Fig. B.2(b)):

$\varepsilon=\varepsilon_{0}+(\chi-\Delta \chi) \cdot(h / 2-\chi)$

As seen in Eq. (B.4), the dilation is calculated using the modified curvature $(\chi-\Delta \chi)$. In this manner, the effect of tension stiffening is taken into account.

- In presence of high tensile axial forces $\left(n>n_{c r}\right)$, the whole concrete cross-section may be cracked in tension. In this case (Fig. B.1(c)), the stiffness of the cross-section consists of the stiffness of only rebars $\beta E I_{s}$ (Fig. B.2(c)). In the case of different compression and tensile reinforcement ratios, the influence of this asymmetry on the location of the neutral axis should be taken into account. It should be noted that the slope can be negative if the amount of compression reinforcement exceeds the amount of tensile reinforcement.

- Between the uncracked and cracked regimes, a crack development plateau is usually assumed. In the current paper, the slope of the plateau is taken equal to $E I_{s}$ as in the previously described regime (Fig. B.1) to ensure continuity between different levels of axial load. However, as a simplification, the curvature-dilation relationship is found with Eq. (B.4) similarly to the cracked regime.

The multi-linear law used for determining the dilation at zero moment $\varepsilon_{0}$ is shown in Fig. B.3(a). Similarly to the moment-curvature relationship, uncracked and cracked regimes are distinguished with the respective stiffnesses of $\beta E A_{0}$ and $\beta E A_{s}$. As a simplification, tension stiffening is neglected in this law. The tensile capacity of the cross-section at zero moment $n_{R}$ is reached when the bars on the side with lower reinforcement ratio start to yield. 
The flexural capacity of the cross-section $\left(m_{R}\right)$ is calculated assuming yielding of tensile reinforcement and a rectangular compression block in concrete:

$m_{R}=\rho \cdot d \cdot f_{y}(d-h / 2)+\rho_{2} \cdot d \cdot f_{y}(d-h / 2)+f_{c} \cdot x_{p l}\left(h / 2-x_{p l} / 2\right)$

where the height of the compression zone $x_{p l}$ depending on the level of axial force can be found with:

$x_{p l}=\left(\left(\rho-\rho_{2}\right) \cdot d \cdot f_{y}-n\right) / f_{c p}$

In the case of high compressive axial force, tensile reinforcement may not be yielding at the flexural limit $\left(\varepsilon_{s}<f_{y} / E_{s}\right.$ in Fig. B.3(b)). In this case, the moment capacity is limited by the strength of the compression zone. By assuming that the ultimate compressive strain of concrete is 3.5\%o, stress in tension reinforcement can be calculated (Fig. B.3(b)):

$\sigma_{s}=\frac{d-x}{x} \cdot 0.0035 \cdot E_{s}$

By further assuming that the height of the rectangular compression block is $0.8 x$, the moment capacity can be found:

$m_{R}=\rho \cdot d \cdot \sigma_{s} \cdot(d-h / 2)+\rho_{2} \cdot d \cdot f_{y}(d-h / 2)+f_{c} \cdot 0.8 x$

$$
\cdot(h / 2-0.8 x / 2)
$$

The equilibrium of normal forces yields an equation:

$n=-\rho \cdot d \cdot \sigma_{s}+\rho_{2} \cdot d \cdot f_{y}+f_{c} \cdot 0.8 x$

Height of the compression zone $x$ and moment capacity $m_{R}$ can be determined by solving the system of Eqs. (B.8) and (B.9). This leads to increasing moment capacity with increasing axial compression but the increase is slower than in the previous regime (Fig. B.3(c)).

If the height of the compression zone reaches the height of the cross-section, increasing the axial force will start to decrease the moment capacity. However, in the current research, high axial compression is only found in the center of the slab and appears simultaneously in radial and tangential direction. Therefore, the ultimate strain and stress of concrete can be significantly higher due to the biaxial compression (confinement). Due to this, for the current analysis it is assumed that the moment capacity does not decrease with increasing axial force (Fig. B.3(c)).

In Fig. 4(d) and (e), the simplified multi-linear law is compared to the results of a non-linear layered sectional analysis. The approaches yield similar results, except for a larger discrepancy regarding the dilation of the cross-section in the case of compressive normal forces and large curvatures. The difference is caused by neglecting concrete compression softening in the simplified law (which reduces the total normal force in the non-linear analysis). However, in the present analysis, large curvatures combined with high axial compressive forces occur in the center of the slab, where the concrete is bi-axially confined and the softening effect is therefore reduced.

\section{Appendix C. Notation}

\footnotetext{
$\mathrm{A}_{\mathrm{i}} \quad$ surface area of an element $i$

$A_{s w} \quad$ total area of shear reinforcement between the column face and a perimeter at distance $d$ from the column

$b_{s} \quad$ width of the support strip according to Model Code 2010 [4]
}

$b_{0} \quad$ perimeter of the critical section at $d / 2$ from the column

c diameter of the column

d effective depth

$\mathrm{d}_{\mathrm{g}} \quad$ maximum aggregate size

$d_{g 0} \quad$ reference aggregate size $\left(d_{g 0}=16 \mathrm{~mm}\right)$

$E A_{0} \quad$ longitudinal stiffness before cracking, per unit width

$E A_{s} \quad$ longitudinal stiffness of the reinforcing bars only, per unit width

$E I_{0} \quad$ flexural stiffness before cracking, per unit width

$E I_{1} \quad$ flexural stiffness after cracking, per unit width

$\mathrm{EI}_{\mathrm{s}} \quad$ flexural stiffness of the reinforcing bars only, per unit width

$\mathrm{E}_{\mathrm{c}} \quad$ modulus of elasticity of concrete (taken as

$\left.E_{c}=10,000 f_{c}^{1 / 3}[4]\right)$

$E_{s} \quad$ modulus of elasticity of reinforcement steel

$\mathrm{f}_{\mathrm{c}} \quad$ concrete cylinder compressive strength

$\mathrm{f}_{\mathrm{ct}} \quad$ concrete tensile strength (taken as $f_{c t}=0.3 f_{c}^{2 / 3}[4]$ )

$\mathrm{f}_{\mathrm{y}} \quad$ yield stress of reinforcing steel

h depth of the slab

$\mathrm{k}_{\mathrm{sys}} \quad$ CSCT coefficient describing the efficiency of a shear reinforcement system $[4,9]$

$\mathrm{L}$ distance between the axes of the columns in a continuous slab (slab span)

$\mathrm{m} \quad$ bending moment per unit width

$\mathrm{m}_{\mathrm{cr}} \quad$ cracking moment per unit width

$m_{r}, m_{t}$ radial bending moment, tangential bending moment, per unit width

$\mathrm{m}_{\mathrm{S}} \quad$ acting bending moment due to the applied load at the column

$\mathrm{m}_{\mathrm{R}} \quad$ moment capacity (yielding moment), per unit width

$m_{R, h o g} \quad$ hogging moment capacity, per unit width

$m_{R, s a g} \quad$ sagging moment capacity, per unit width

$\mathrm{n}$ axial force per unit width

$\mathrm{n}_{\mathrm{cr}} \quad$ tensile cracking force of a cross-section, per unit width

$n_{r}, n_{t} \quad$ radial axial force, tangential axial force, per unit width

$\mathrm{n}_{\mathrm{R}} \quad$ tensile strength of a cross-section at zero moment, per unit width

q distributed load

$\mathrm{r}_{\mathrm{i}} \quad$ distance from the center of the slab to a point $i$

$r_{c} \quad$ radius of the column

$\mathrm{r}_{\mathrm{q}} \quad$ distance between the center of the slab and the point of application of load

$r_{s} \quad$ distance between the center of the slab and the line of moment contraflexure

$\mathrm{r}_{\text {slab }} \quad$ radius of the modeled slab

$\mathrm{u}_{\mathrm{i}} \quad$ horizontal radial displacement of a point $i$ in the slab

$\mathrm{V}$ shear force

$V_{\text {flex,cont }}$ flexural strength of a continuous slab

$V_{\text {flex,isol }} \quad$ flexural strength of an isolated slab

$V_{\text {flex,yl }} \quad$ flexural strength of an slab calculated with yield line method

$V_{R} \quad$ punching shear capacity

$V_{R, \text { cont }}$ punching shear capacity, continuous model

$V_{R, i s o l} \quad$ punching shear capacity, isolated model

$V_{R, t e s t}$ experimental punching shear capacity

$\mathrm{W}$ maximum vertical displacement (deflection) of the slab

$\mathrm{w}_{\mathrm{i}} \quad$ vertical displacement (deflection) of a point $\mathrm{i}$ in the slab

$\mathrm{x}$ distance between the compressed edge of the crosssection and the neutral axis in bending 
$\mathrm{X}_{\mathrm{pl}} \quad$ height of the rectangular compression block

$\beta \quad$ factor that takes into account the orthogonal placement of the reinforcement

$\delta$

$\Delta \chi \quad$ change of curvature

$\Delta \chi_{N} \quad$ change of curvature due to the presence of normal forces

$\Delta \chi_{T-S} \quad$ change of curvature due tension stiffening

$\varepsilon \quad$ dilation of the central axis of a cross-section

$\varepsilon_{\mathrm{cr}} \quad$ dilation of the central axis immediately before cracking

$\varepsilon_{r, t} \quad$ radial, tangential dilation of a slab

$\varepsilon_{S} \quad$ strain in the level of tensile reinforcement

$\varepsilon_{0} \quad$ dilation of the central axis at zero curvature

$\rho \quad$ tension reinforcement ratio

$\rho_{2} \quad$ compression reinforcement ratio

$\rho_{\text {hog }} \quad$ hogging flexural reinforcement ratio

$\rho_{\text {sag }} \quad$ sagging flexural reinforcement ratio

$\sigma_{\mathrm{n}} \quad$ axial stress in the cross-section at the control perimeter

$\sigma_{\mathrm{s}} \quad$ stress in tension reinforcement

$\chi \quad$ curvature of a cross-section

$\chi_{\mathrm{cr}} \quad$ curvature of a cross-section immediately before cracking

$\chi_{r}, \chi_{t}$ radial curvature, tangential curvature

$\psi \quad$ rotation of the slab at the line of moment contraflexure

$\psi^{\prime} \quad$ modified rotation to take into account the axial compression at the control perimeter

$\psi_{\mathrm{i}} \quad$ rotation of the slab at a point $\mathrm{i}$

$\psi_{\mathrm{R}} \quad$ rotation of a slab at the line of moment contraflexure at punching failure

\section{References}

[1] Eurocode 2. Design of concrete structures - part 1: general rules and rules fo buildings. European Committee for Standardization (CEN), Brussels, Belgium; 2004. 225p.

[2] Building Code Requirements for Structural Concrete, ACI 318-11. American Concrete Institute, ACI Committee 318, USA; 2011. 503p

[3] Muttoni A. Punching shear strength of reinforced concrete slabs without transverse reinforcement. ACI Struct J 2008:105(4):440-50 [USA].

[4] fib Model Code for Concrete Structures 2010. Fédération internationale du béton. Ernst \& Sohn, Germany; 2013. 434p.

[5] Muttoni A, Fernández Ruiz M, Bentz EC, Foster SJ, Sigrist V. Background to the Model Code 2010 shear provisions - part II punching shear. Struct Concr 2013;14(3):195-203 [Ernst \& Sohn, Berlin, Germany].

[6] Kinnunen S, Nylander H. Punching of concrete slabs without shear reinforcement. Stockholm, Sweden: Transactions of the Royal Institute of Technology No. 158; 1960. 112p.

[7] Shehata IAEM, Regan PE. Punching in R.C. Slabs. J Struct Eng 1989:115(7):1726-40 [USA].

[8] Broms CE. Punching of flat plates - a question of concrete properties in biaxial compression and size effect. ACI Struct J 1990;87(3):292-304 [USA]

[9] Fernández Ruiz M, Muttoni A. Applications of Critical Shear Crack Theory to punching of reinforced concrete slabs with transverse reinforcement. $\mathrm{ACl}$ Struct J 2009;106(4):485-94 [USA].

[10] Maya Duque LF, Fernández Ruiz M, Muttoni A, Foster SJ. Punching shear strength of steel fibre reinforced concrete slabs. Eng Struct 2012:40:93-4 [UK].

[11] Clément T, Pinho Ramos A, Fernández Ruiz M, Muttoni A. Influence of prestressing on the punching strength of post-tensioned slabs. Eng Struct 2014;72:56-69 [UK].

[12] Guandalini S. Poinçonnement symétrique des dalles en béton armé. PhD thesis, EPFL no. 3380, Lausanne, Switzerland; 2005. 289p. [in French].

[13] Clément T, Ramos AP, Fernández Ruiz M, Muttoni A. Design for punching of prestressed concrete slabs. Struct Concr 2013;14(2):157-67 [Lausanne, Switzerland].

[14] Sagaseta J, Muttoni A, Fernández Ruiz M, Tassinari L. Non-axis-symmetrical punching shear around internal columns of RC slabs without transverse reinforcement. Mag Concr Res 2011:63(6):441-57 [UK].

[15] Sagaseta J, Tassinari L, Fernández Ruiz M, Muttoni A. Punching of flat slabs supported on rectangular columns. Eng Struct 2014;77:17-33 [UK].

[16] Ockleston AJ. Load tests on a three storey reinforced concrete building in Johannesburg. Struct Eng 1955;33(10):304-22 [United Kingdom].

[17] Ladner M, Schaeidt W, Gut S. Experimentelle Untersuchungen an StahlbetonFlachdecke. EMPA Bericht no. 205, Switzerland; 1977. 96p. [in German].

[18] Chana BS, Desai SB. Membrane action, and design against punching shear. Struct Eng 1992;70(19):339-43 [United Kingdom].

[19] Choi JW, Kim J-H. Experimental investigations on moment redistribution and punching shear of flat plates. ACI Struct J 2012;109(3):329-38 [USA].

[20] Wood RH. Plastic and elastic design of slabs and plates. United Kingdom: Thames and Hudson; 1961. 344p.

[21] Park R, Gamble WL. Reinforced concrete slabs. USA: John Wiley \& Sons; 1980. $618 p p$.

[22] Braestrup MW. Dome effect in RC slabs: rigid-plastic analysis. J Struct Div ASCE 1980;106(6):1237-53 [USA].

[23] Melo GS, Regan PE. Post-punching resistance of connections between flat slabs and interior columns. Mag Concr Res 1998;50(4):319-27 [USA].

[24] Fernández Ruiz M, Mirzaei Y, Muttoni A. Post-punching behavior of flat slabs. ACI Struct J 2013;110(5):801-12 [USA]

[25] Braestrup MW, Morley CT. Dome effect in RC slabs: elastic-plastic analysis. J Struct Div - ASCE 1980;106(6):1255-62 [USA].

[26] Kirkpatrick J, Rankin GIB, Long AE. Strength evaluation of M-beam bridge deck slabs. Struct Eng 1984;62B(3):60-8 [UK].

[27] UK Highway Agency. BD 81/02 use of compressive membrane action in bridge decks. Design manual for roads and bridges, vol. 3, Section 4, Part 20; August 2002. 20pp.

[28] Hewitt BE, Batchelor B. Punching shear strength of restrained slabs. J Struct Div - ASCE 1975;101(9):1837-53 [USA].

[29] Kuang JS, Morley CT. A plasticity model for punching shear of laterally restrained slabs with compressive membrane action. Int J Mech Sci 1993;35(5):371-85 [United Kingdom].

[30] Eyre JR. Surround stiffness to membrane action in concrete slabs. Mag Concr Res 2007;59(2):107-19 [United Kingdom].

[31] Belletti B, Vitulli F, Walraven JC. Compressive membrane action in confined RC and SFRC circular slabs. In: Computational modelling of concrete structures, United Kingdom; 2014. p. 807-18.

[32] Muttoni A, Fernández Ruiz M, Einpaul J. Punching strength of actual two-way slabs. In: 4th fib congress, Mumbai, India; 2014. 6p.

[33] Staller M. Empirical model by Staller. fib Bulletin 12: punching of structural concrete slabs. Fédération internationale du béton, Switzerland; 2001. p. 5661.

[34] Tassinari L. Poinçonnement non symétrique des dalles en béton armé. PhD thesis, EPFL no. 5030, Lausanne, Switzerland; 2011. 197p. [in French].

[35] Lips S, Fernández Ruiz M, Muttoni A. Experimental investigation on punching strength and deformation capacity of shear-reinforced slabs. ACI Struct J 2012;109(6):889-900 [USA].

[36] Stein T, Ghali A, Dilger WH. Distinction between punching and flexural failure modes of flat plates. ACI Struct J 2007;104(3):357-65 [USA]. 